\title{
Sub-Saharan Northern African climate at the end of the twenty-first century: forcing factors and climate change processes
}

\author{
C. M. Patricola $\cdot$ K. H. Cook
}

Received: 27 May 2010/ Accepted: 5 September 2010/Published online: 29 September 2010

(C) The Author(s) 2010. This article is published with open access at Springerlink.com

\begin{abstract}
A regional climate model, the Weather Research and Forecasting (WRF) Model, is forced with increased atmospheric $\mathrm{CO}_{2}$ and anomalous SSTs and lateral boundary conditions derived from nine coupled atmosphere-ocean general circulation models to produce an ensemble set of nine future climate simulations for northern Africa at the end of the twenty-first century. A well validated control simulation, agreement among ensemble members, and a physical understanding of the future climate change enhance confidence in the predictions. The regional model ensembles produce consistent precipitation projections over much of northern tropical Africa. A moisture budget analysis is used to identify the circulation changes that support future precipitation anomalies. The projected midsummer drought over the Guinean Coast region is related partly to weakened monsoon flow. Since the rainfall maximum demonstrates a southward bias in the control simulation in July-August, this may be indicative of future summer drying over the Sahel. Wetter conditions in late summer over the Sahel are
\end{abstract}

\footnotetext{
C. M. Patricola
}

Department of Earth and Atmospheric Sciences,

Cornell University, 3152 Snee Hall, Ithaca, NY 14853, USA

\section{K. H. Cook}

Department of Geological Sciences, Jackson School

of Geosciences, The University of Texas at Austin,

1 University Station, C1100 Austin, TX 78712, USA

Present Address:

C. M. Patricola $(\square)$

Department of Atmospheric Sciences, Texas A\&M University,

College Station, TX 77843, USA

e-mail: cmd58@cornell.edu associated with enhanced moisture transport by the West African westerly jet, a strengthening of the jet itself, and moisture transport from the Mediterranean. Severe drought in East Africa during August and September is accompanied by a weakened Indian monsoon and Somali jet. Simulations with projected and idealized SST forcing suggest that overall SST warming in part supports this regional model ensemble agreement, although changes in SST gradients are important over West Africa in spring and fall. Simulations which isolate the role of individual climate forcings suggest that the spatial distribution of the rainfall predictions is controlled by the anomalous SST and lateral boundary conditions, while $\mathrm{CO}_{2}$ forcing within the regional model domain plays an important secondary role and generally produces wetter conditions.

\section{Introduction}

There is a vital need for trustworthy predictions of subSaharan northern African climate since the region is highly agricultural and prone to devastating droughts. Simulations from the majority of the atmosphere-ocean general circulation models (AOGCMs) run for the Fourth Assessment Report of the Intergovernmental Panel on Climate Change (IPCC AR4; IPCC 2007) produce weak annual-mean rainfall projections over this region. One model produces extreme rainfall decreases (Held et al. 2005), and one produces extreme increases, but these outlier model simulations may not be accurate (Cook and Vizy 2006; Giannini et al. 2008; Cook 2008).

Many of the AOGCMs validate poorly over northern Africa, e.g., incorrectly simulating the summer precipitation maximum over the Gulf of Guinea instead of over the continent, and misrepresenting basic circulation features of 
the West African monsoon (Cook and Vizy 2006). Patricola and Cook (2010) developed an approach for projecting future climate that combines the advantages of global and regional modeling. They produce a nine-member ensemble of climate simulations for the end of the twenty-first century over northern Africa by constraining a regional climate model, the Weather Research and Forecasting (WRF) Model (Skamarock et al. 2005), with SST and lateral boundary condition anomalies derived from each of nine AOGCMs. There is a very good consensus regarding the sign of the predicted rainfall anomalies of the regional model ensemble members, with at least $77 \%$ (7 of 9) of the ensemble members in agreement over vast regions of subSaharan northern Africa. This is a substantial improvement over the projections from the AOGCMs that provided the anomalous SST and lateral boundaries to constrain the regional model, even though those SST and lateral boundary predictions vary among the nine global models. They note that there is some uncertainty in the predictions over the Sahel in July and August since the northward migration of the rainfall band is underestimated during those months in the control simulation.

Patricola and Cook (2010) describe the prediction method in detail and report climate change predictions. Confidence in these predictions is founded on the agreement among the ensemble members and on the ability of the regional model to capture an accurate portrayal of the present day climate dynamics of northern Africa. The purpose of this paper is to further enhance confidence in these predictions and to expand our basic understanding of the region's climate by developing a physical understanding of the simulated climate change through analysis of the dynamics of the West African monsoon and East African region in the future. We investigate the role of individual climate change forcing factors, and explain why the rainfall predictions are similar among the nine future regional model ensembles despite differences in the forcing, especially SSTAs, taken from the AOGCM projections.

\section{Background}

In this section, we summarize the climate predictions of Patricola and Cook (2010), hereafter PC10, so that we may build on those results in this paper. In addition, we review present day relationships between variability in precipitation and circulation features over northern tropical Africa to guide the supporting dynamical analysis of the future climate. For a review of AOGCM predictions, the ability of models to simulate present day relationships between SSTs and West African rainfall, and land-atmosphere interactions, please see PC10.
2.1 Sub-Saharan northern African climate predictions from PC10

The AOGCM simulations conducted for the IPCC AR4 (IPCC 2007) produced summer rainfall predictions for the Sahel at the end of the twenty-first century that, as Cook (2008) notes, are clustered around zero with the exception of one extremely wet and one extremely dry outlier. It is unclear from this multi-model ensemble approach whether West African summer rainfall is expected to increase, decrease, or remain about the same in the future. A validation-based approach, in which future projections are considered from only models that reasonably represent the present day climate and one prominent mode of interannual variability over West Africa, does not produce a consensus about the sign of the future precipitation anomalies (Cook and Vizy 2006). This suggests that while a realistic representation of the control climate supports confidence, it is not sufficient for reliable prediction, and as Cook and Vizy (2006) note, emphasizes the need for an approach that relies on our physical understanding of the region. Although the AOGCMs do not produce a clear prediction of summer-averaged rainfall, a recent study by Biasutti and Sobel (2009) identifies a more consistent future Sahelian rainfall signal when AOGCM output is analyzed on the monthly rather than seasonal timescale. They find a delay in the rainy season, with most models simulating drier (wetter) conditions in May and June (October).

PC10 discuss the disadvantages that arise from depending solely on global models to simulate regional climate change, specifically difficulty in representing the present day climate and coarse model resolution that does not resolve the observed low-level jets (e.g., the West African westerly jet and Turkana jet) and meridional gradients in precipitation, moisture, and temperature. In order to address these issues, PC10 developed a method that combines the advantages of both the global and regional modeling approaches. Using a regional model offers the benefit of simulating at an appropriate resolution, chosen through testing to capture important surface and atmospheric features, as well as producing model output that is more suitable for impacts analysis. In addition, regional modeling offers the ability to select an optimal set of parameterizations and land surface model for a realistic simulation of northern African climate, which PC10 demonstrated is critically important. The coupled global models provide predictions of SST and lateral boundary condition anomalies that are needed to drive the future regional climate simulations.

The method used by PC10 devotes particular attention to uncertainties in future SST and lateral boundary conditions by forming an ensemble of nine future climate simulations. Each of the ensemble members are forced with anomalies 
(a)

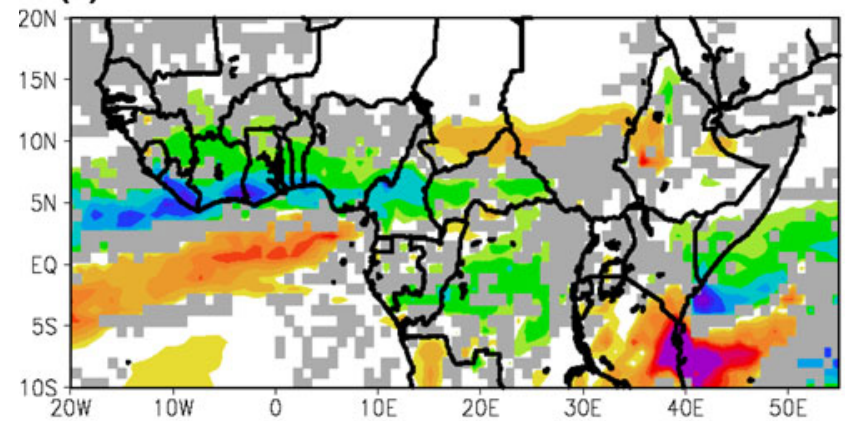

(c)

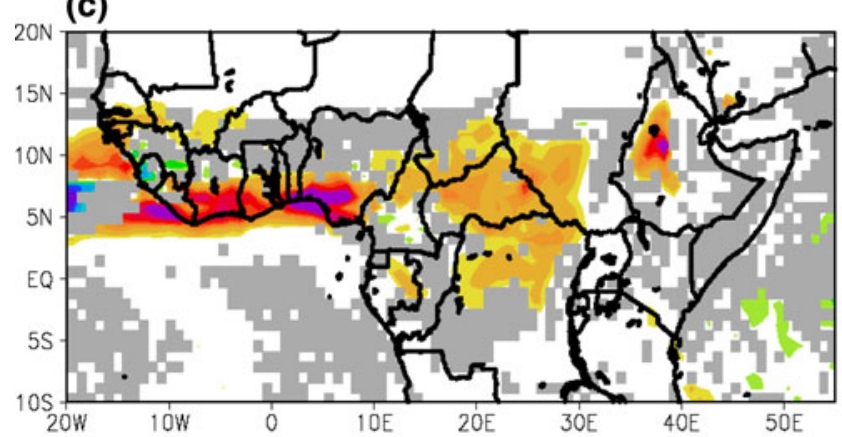

(e)

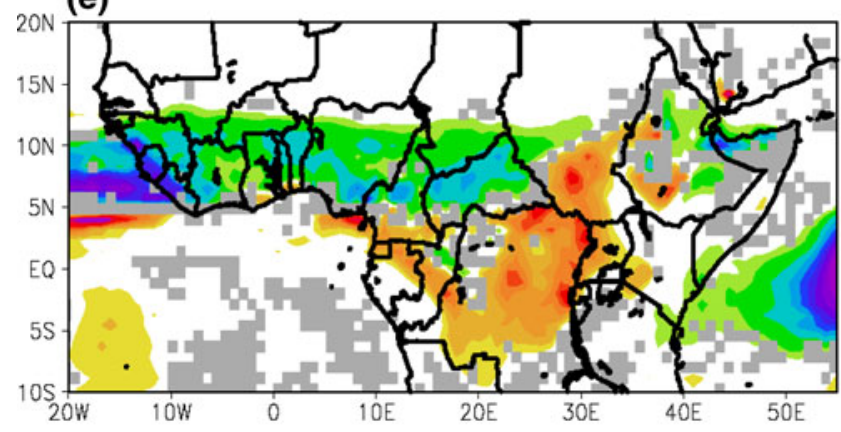

(b)

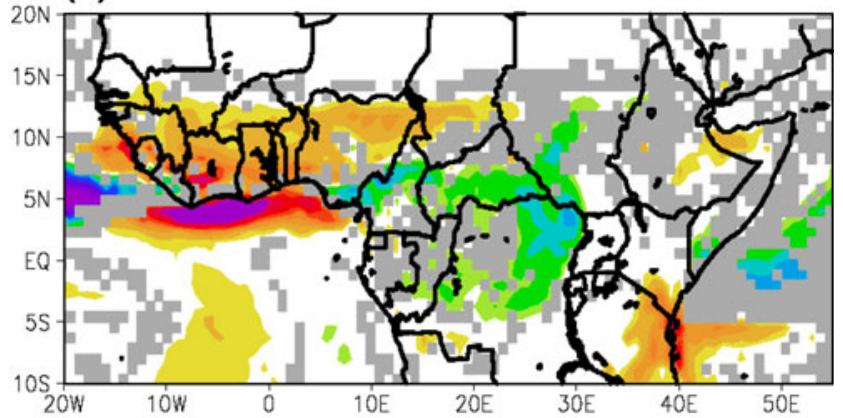

(d)

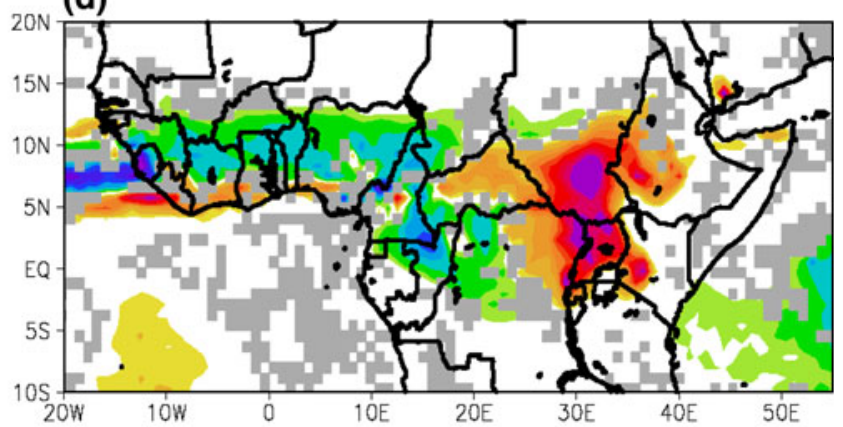

(f)

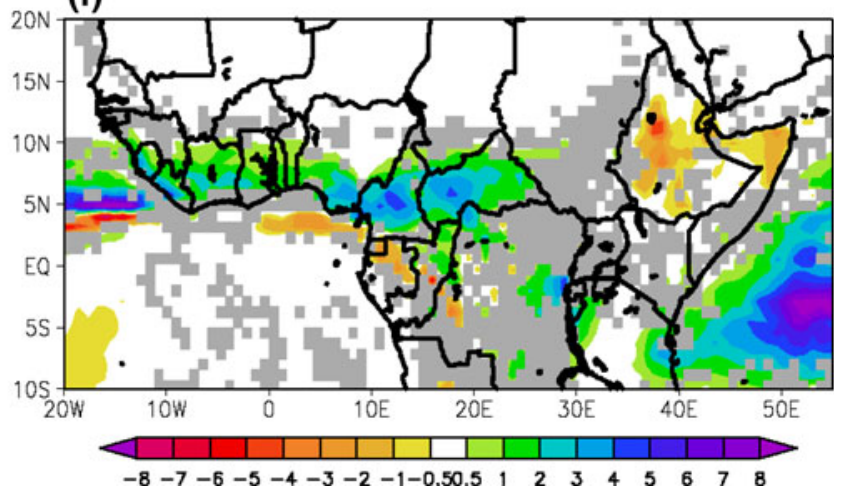

Fig. 1 Ensemble averaged precipitation anomalies (2081-2100 minus 1981-2000) from the fully forced future simulations for a May, b June, c July, d August, e September, and f October. Units are $\mathrm{mm} /$ day. Areas where $<77 \%$ of the ensemble members agree are shaded grey

in boundary conditions derived from each of nine different AOGCMs. The formulation of boundary conditions in PC10 differs from the traditional dynamical downscaling method, in which SSTs and lateral boundary conditions are applied directly from an AOGCM to a regional model. Here, anomalies from AOGCMs are added to the present day climatology of reanalysis products to create the future boundary conditions that drive the regional climate model. This is done in order to reduce the impact of GCM error on the regional projections, and to produce a well-validated control climate constrained by reanalysis products. The AOGCM anomalies are differences between the present day (1981-2000) and future (2081-2100) climatologies forced by the SRESA2 emissions scenario (IPCC 2000).

Figure 1 shows the ensemble-averaged monthly rainfall predictions for 2081-2100 from PC10's regional climate model simulations, with regions where $<77 \%$ of the ensemble members ( 7 out of 9) agree on the sign of the precipitation anomaly shaded in grey. The nine ensemble members produce monthly rainfall predictions that are consistent in sign over much of sub-Saharan northern Africa (Fig. 1). Wetter conditions are predicted over the Guinean Coast region in May, September, and October with drying from June through August. Note that drying over the Guinean Coast is predicted in July-August when precipitation is overestimated (underestimated) over the Guinean Coast (Sahel) in the control simulation. Given the bias in the location of the precipitation band, this may indicate future drying over the Sahel. Over the Sahel region, drier conditions are predicted in June and wetter conditions that may result in an increased flood risk persist from August through October. In East Africa, severe drying 
(a)
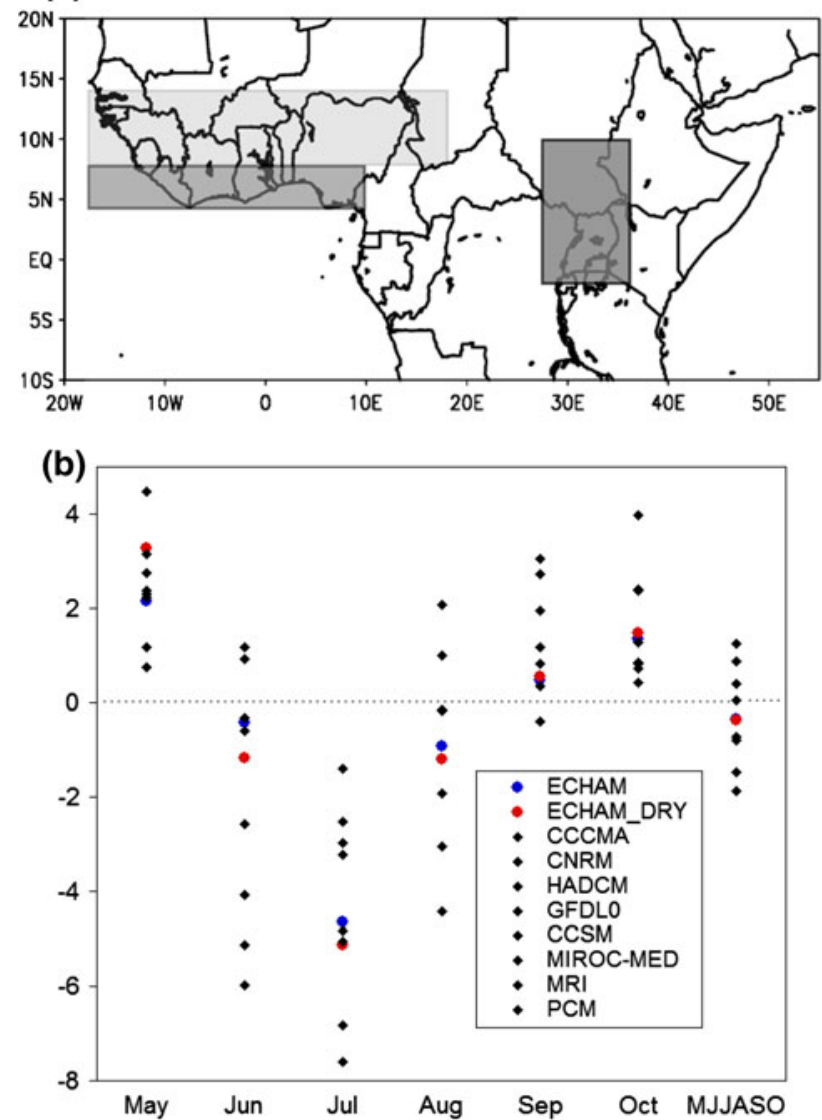

(c)

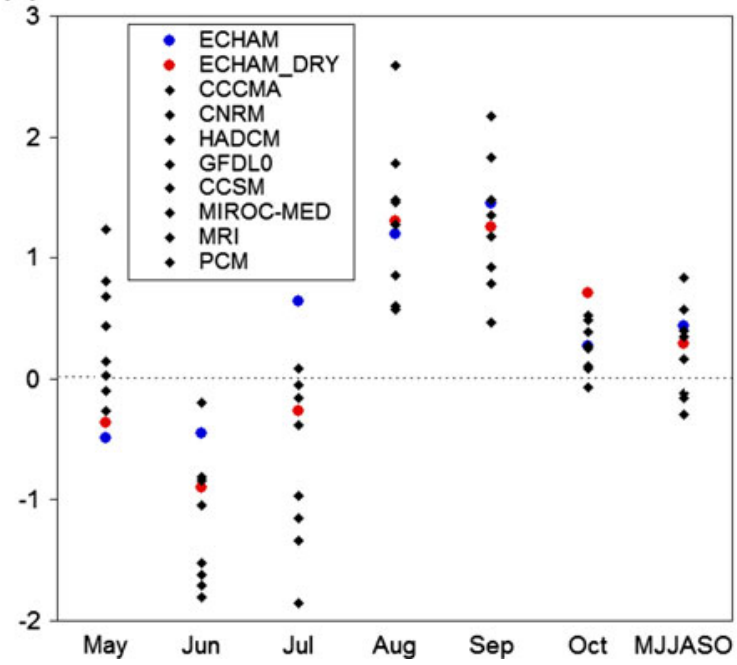

Fig. 2 a Averaging regions including the Sahel (light grey), Guinean Coast (medium grey), and East Africa (dark grey). Monthly and MJJASO averaged precipitation anomalies from the nine individual fully forced future simulations and the 21_DRY simulation over land only for the (b) Guinean Coast and (c) Sahel regions. Units are mm/day

is centered over southern Sudan and Uganda in August and September (Fig. 1d, e).

Figure 2 shows the monthly and MJJASO averaged, areaaveraged precipitation anomalies from each individual ensemble member over West Africa to provide more detailed information about the level of agreement of the ensemble average rainfall predictions, and the averaging regions (Fig. 2a) used throughout the analysis, which include the Sahel $\left(8^{\circ} \mathrm{N}-14^{\circ} \mathrm{N}\right.$ and $\left.18^{\circ} \mathrm{W}-18^{\circ} \mathrm{E}\right)$ and Guinean Coast $\left(4^{\circ} \mathrm{N}-7.5^{\circ} \mathrm{N}\right.$ and $\left.18^{\circ} \mathrm{W}-10^{\circ} \mathrm{E}\right)$ in West Africa, and East Africa $\left(2^{\circ} \mathrm{S}-10^{\circ} \mathrm{N}\right.$ and $\left.28^{\circ} \mathrm{E}-36^{\circ} \mathrm{E}\right)$. Over the Guinean Coast region in May, when at least $77 \%$ of the ensemble members predict wetter conditions (Fig. 1a), none of the ensemble members are drastic outliers in the rainfall predictions (Fig. 2b). This holds true for each month in which $77 \%$ of the ensemble members agree on the sign of the rainfall anomaly over both the Guinean Coast (Fig. 2b) and Sahel (Fig. 2c) regions. In addition, when the ensemble members do not agree on the sign of the rainfall prediction, for example, over the Sahel in May (Fig. 1a), the individual model predictions (Fig. 2c) cluster close to zero, and none of the members are outliers. In July, when predictions are also uncertain over the Sahel (Fig. 1c), four of the members produce drying of 1-2 $\mathrm{mm} /$ day, four of the models produce near-zero change, and one model produces wetter conditions of $\sim 0.75 \mathrm{~mm} /$ day (Fig. $2 \mathrm{c}$ ), suggesting the Sahel may be weakly dry during July in the future. Even when the ensembles disagree about the sign of the rainfall anomaly the range of the predicted anomalies is small, promoting confidence in the precipitation predictions.

The May-October average for each of the nine future regional climate ensemble predictions for the Guinean Coast and Sahel regions is in the last column of Fig. $2 \mathrm{~b}$ and c, respectively. For both regions, the 6-month averages are clustered closely about zero change; over the Guinean Coast the anomalies are evenly distributed around zero, while over the Sahel the anomalies tend to be positive. This result is similar to the summer rainfall predictions for 2100 from the AOGCMs run for the IPCC AR4, which are clustered around $\pm 0.5 \mathrm{~mm} /$ day with two outliers reaching about $2 \mathrm{~mm} /$ day and $-2.75 \mathrm{~mm} /$ day, suggesting that on the seasonal timescale Sahelian rainfall anomalies in the future may indeed be weak. However, this is not the case for the monthly rainfall predictions, which, similar to the results of Biasutti and Sobel (2009), highlights the importance of analyzing rainfall predictions on at least the monthly timescale. Information that is critical for impacts analysis can be missed by focusing on only the annual or seasonal averages.

\subsection{Climate variability: West Africa}

One way to support confidence in projections of future climate change is to understand the physical processes responsible for the change, and evaluate the extent to which those processes are reasonable given our current understanding of the system. Here we briefly review the known relationships between circulation features and 
sub-Saharan northern African rainfall to assist in the analysis below.

The West African monsoon is supported by moist southerly winds from the Gulf of Guinea that converge with the dry northeasterly Harmattan winds (e.g. Cook 1997; Sultan and Janicot 2003). Moisture transport associated with the more recently identified low-level West African westerly jet (WAWJ) on the west coast near $10^{\circ} \mathrm{N}-12.5^{\circ} \mathrm{N}$ (Grodsky et al. 2003) provides an important additional moisture source, especially for the Sahel $(\mathrm{Pu}$ and Cook 2010a). Variability in the WAWJ is associated with Sahel rainfall on decadal timescales, with a stronger jet and wetter conditions tending to occur together ( $\mathrm{Pu}$ and Cook 2010b). The WAWJ is also important on geological timescales, with a stronger jet supporting the "green Sahara" conditions in regional climate simulations of 6,000 years ago (Patricola and Cook 2007). This jet may also be an important feature in abrupt climate change processes. Patricola and Cook (2008) find that small changes in the strength of the WAWJ are simulated as gradual idealized vegetation changes are imposed south of a threshold latitude in a regional climate model, while a large change in the jet strength is simulated when small vegetation changes are imposed at the threshold latitude. The African easterly jet (AEJ), located on the west coast of Africa at about $15^{\circ} \mathrm{N}$ and $625 \mathrm{hPa}$, is a moisture sink for the West African monsoon (Cook 1999). In today's climate, a stronger AEJ that is located anomalously south is associated with dry conditions in the Sahel on interannual time scales (Newell and Kidson 1984; Fontaine et al. 1995; Grist and Nicholson 2001).

Many studies have found relationships between present day variability in West African rainfall and Atlantic SSTs on interannual to decadal timescales. Wetter (drier) conditions over the Sahel tend to be associated with warmer (cooler) northern and cooler (warmer) southern tropical and subtropical Atlantic SSTs (Lamb 1978a and 1978b; Folland et al. 1986, 1991; Druyan 1991; Lamb and Peppler 1992; Ward 1998). SSTs in the Gulf of Guinea exert a significant influence on West African rainfall as well. One frequently observed mode of interannual variability is manifest as a dipole pattern with wet (dry) conditions over the Guinean Coast region and dry (wet) conditions over the Sahel in association with warm (cool) Gulf of Guinea SSTs (Nicholson 1980; Janicot 1992; Rowell et al. 1995). Regional climate model simulations capture this dipole pattern (Vizy and Cook 2002). The drying over the Sahel is associated with subsidence that results from shrinking of planetary vorticity and enhanced relative vorticity advection in the outflow from the Saharan high, while the wetter conditions over the Guinean Coast are linked to an increase in moisture transport across the Guinean coast through enhanced evaporation over the ocean, and not through a strengthening of the low-level southerly monsoon flow.
Both observations and model simulations reveal a relationship between Mediterranean SSTs and Sahel rainfall such that warmer (cooler) SSTs in the Mediterranean are associated with a wetter (drier) Sahel, most strongly on the decadal time scale (Rowell 2003). AGCM simulations indicate that a warm Mediterranean results in increased local evaporation, and that additional moisture is advected to the south at low levels and supports moisture convergence anomalies over the Sahel. The rainfall further is enhanced by several positive feedbacks, including a weakening of the African easterly jet.

Indian Ocean SSTs have been found to influence Sahelian rainfall on decadal timescales as well, with overall warming contributing to drier conditions (Giannini et al. 2003; Bader and Latif 2003; Lu and Delworth 2005) and dominating wetter conditions produced by a weakening of the meridional Indian Ocean SST gradient (Chung and Ramanathan 2006). Climate simulations produce a Rossby wave response with convergence over the Indian Ocean and divergence over Africa due to Indian Ocean warming (Hagos and Cook 2008; Lu 2009). However, regional climate simulations demonstrate that the location of the subsidence depends on the scale and magnitude of the Indian Ocean forcing. Although the Indian Ocean was anomalously warm during both the 1980s and 1990s, the rainfall response over West Africa was different because the region of subsidence shifted to the west-off the coast - in the 1990s and allowed for the current observed recovery in Sahel rainfall (Hagos and Cook 2008).

\subsection{Climate variability: East Africa}

The Somali jet (Findlater 1966, 1977) is a cross-equatorial low-level jet that is southerly over the Horn of Africa and turns westerly into the Arabian Sea, transporting significant amounts of moisture over East Africa and into the Asian monsoon. A strong Somali jet is associated with above normal rainfall over the Horn of Africa (Segele et al. 2009) as well as wetter conditions along the west coast of India (Halpurn and Woiceshyn 2001). Camberlin (1997) finds that, throughout the twentieth century, above normal sea-level pressure over Bombay and Indian drought in July through September are not only strongly correlated with dry conditions in the Ethiopian Highlands, Uganda, and western Kenya, but also precede them, suggesting that the Indian monsoon may be in part controlling rainfall in East Africa. Vizy and Cook (2003) also find that a strong (weak) Somali jet occurs with a wet (dry) Indian monsoon in regional model simulations but, unlike the observations, northern Ethiopian drying accompanied by decreased convergence and stronger flow in the Somali jet entrance region occurs with an enhanced Indian monsoon. 
Another circulation feature over East Africa that is related to rainfall variations is the Turkana Channel jet, which is a low-level southeasterly jet that funnels between the Ethiopian Highlands and the East African highlands. It persists throughout the year, and is formed by orographic channeling of the flow (Kinuthia and Asnani 1982; Kinuthia 1992). A negative correlation between the strength of the Turkana jet and the Somali jet is found in regional model simulations (Vizy and Cook 2003), although the authors note that the Turkana jet should be investigated further with higher resolution simulations. Regional model simulations also produce a negative correlation between the strength of the Turkana jet and rainfall over that region, with a stronger (weaker) jet associated with stronger (weaker) low-level divergence (Sun et al. 1999).

\section{Methodology}

Regional climate model (RCM) simulations are conducted with the Weather Research and Forecasting Model (WRF; Skamarock et al. 2005) Version 2.2 with a set of parameterizations chosen for an optimal simulation of northern African climate (see PC10). The horizontal resolution is $90 \mathrm{~km}$, and the domain (see Fig. 1 in PC10) includes Africa, the Mediterranean Sea, and the tropical and subtropical Atlantic and Indian Oceans.

This study is based on the present day and future simulations described in PC10 and listed in the first two rows of Table 1. These are climate mode simulations that include one control simulation representative of 1981-2000, with SSTs and lateral boundary conditions (LBCs) prescribed from climatological monthly means of the European Center for Medium Range Weather Forecasting ERA-40 reanalysis (ECMWF 2002) and the National Center for Environmental Prediction/National Center for Atmospheric Research (NCEP/NCAR; Kalnay et al. 1996) reanalysis, respectively. The atmospheric $\mathrm{CO}_{2}$ concentration is set to $330 \mathrm{ppm}$. The integrations are run from March 15 to October 31, with March 15-April 30 disregarded for spin-up. PC10 provide a detailed description of this simulation along with validation that demonstrates that the control simulation is comparable to or better than those from the current generation of AOGCMs.

The future simulations are an ensemble of nine simulations that represent the climate for 2081-2100. Each simulation is constrained by SST anomalies (SSTAs) and lateral boundary condition anomalies (LBCAs) from each of nine AOGCMs, and the $\mathrm{CO}_{2}$ concentration is increased to $757 \mathrm{ppm}$ based on the SRESA2 emissions scenario (IPCC 2000). Boundary conditions are derived from nine AOGCM simulations which are included in the World Climate Research Programme's (WCRP's) Coupled Model Intercomparison Project phase 3 (CMIP3) multimodel dataset (Meehl et al. 2007) and archived by the Program for Climate Model Diagnosis and Intercomparison. Please refer to $\mathrm{PC} 10$ for a detailed description of these simulations.

The moisture budget, similar to that derived in Lenters and Cook (1995), is used to develop an understanding of the connections between simulated precipitation and circulation anomalies. The vertically integrated atmospheric moisture budget is

$P=E+C+A+R$,

which calculates the contributions to precipitation $(\mathrm{P})$ from evaporation $(E)$, vertically integrated moisture convergence (C) and advection (A), and the residual (R) which includes topographical effects as well as numerical and sampling error. (As pointed out by Lenters and Cook (1995), the term "convergence" is used loosely here and represents the product of the water vapor mixing ratio and wind convergence.) The contribution from vertically integrated moisture convergence is

Table 1 List of simulations

\begin{tabular}{lllllc}
\hline Name & $\mathrm{CO}_{2}$ (ppm) & SST & LBC & $\begin{array}{l}\text { AOGCM providing } \\
\text { SSTA and LBCA }\end{array}$ & Initial soil conditions \\
\hline Control (1 run) $^{\mathrm{a}}$ & & & & March 1981-2000 \\
Fully forced future (9 runs) $^{\mathrm{a}}$ & 757 & $1981-2000$ & $1981-2000$ & - & March 1981-2000 \\
SSTA_only (9 runs) & 330 & $2081-2100$ & $2081-2100$ & 9 AOGCMs & March 1981-2000 \\
2K_SSTA (1 run) & 330 & $2081-2100$ & $1981-2000$ & 9 AOGCMs & March 1981-2000 \\
CO2_only (1 run) & 757 & $1981-2000$ & $1981-2000$ & - & March 1981-2000 \\
LBCA_only_EC (1 run) & 330 & $1981-2000$ & $2081-2100$ & ECHAM & March 1981-2000 \\
SSTA + LBCA_EC (1 run) & 330 & $2081-2100$ & $2081-2100$ & ECHAM & March 1981-2000 \\
21_DRY (1 run) & 757 & $2081-2100$ & $2081-2100$ & ECHAM & March of 4 dry years \\
\hline
\end{tabular}

${ }^{a}$ Simulations completed in PC10 
$C=-\frac{1}{g \rho_{w}} \sum_{p=p_{s}}^{100 h P a}\left(q \nabla_{h} \cdot \vec{V}\right) \Delta p$,

where $\mathrm{g}$ is the acceleration due to gravity, $\rho_{w}$ is the density of water, $\mathrm{p}$ is pressure, $\mathrm{p}_{\mathrm{s}}$ is surface pressure, $\mathrm{q}$ is the water vapor mixing ratio, $\vec{V}$ is the horizontal wind vector, and $\nabla_{h}$ is the horizontal divergence operator.

The contribution from vertically integrated moisture advection is

$A=-\frac{1}{g \rho_{w}} \sum_{p=p_{s}}^{100 h P a}\left(\vec{V} \cdot \nabla_{h} q\right) \Delta p$

The moisture convergence and advection terms are expressed in component form as

$$
\begin{aligned}
& C_{M}=-\frac{1}{g \rho_{w}} \sum_{p=p_{s}}^{100 h P a}\left(q \nabla_{h} \cdot v\right) \Delta p, \\
& C_{Z}=-\frac{1}{g \rho_{w}} \sum_{p=p_{s}}^{100 h P a}\left(q \nabla_{h} \cdot u\right) \Delta p, \\
& A_{M}=-\frac{1}{g \rho_{w}} \sum_{p=p_{s}}^{100 h P a}\left(v \cdot \nabla_{h} q\right) \Delta p, \\
& A_{Z}=-\frac{1}{g \rho_{w}} \sum_{p=p_{s}}^{100 h P a}\left(u \cdot \nabla_{h} q\right) \Delta p,
\end{aligned}
$$

where $C_{M}\left(A_{M}\right)$ and $C_{Z},\left(A_{Z}\right)$, are vertically integrated meridional and zonal moisture convergence (advection), respectively.

Fourteen additional simulations, also listed in Table 1, are conducted to better understand the role of individual climate forcings, namely, atmospheric $\mathrm{CO}_{2}$ concentration, SSTAs, and LBCAs. An ensemble of nine simulations designed to isolate the impact of SSTAs on climate is forced with SSTAs for 2081-2100 from each of the nine AOGCMs (as in the fully forced future runs, see Fig. 3 in PC10), with LBCs and $\mathrm{CO}_{2}$ representing 1981-2000. Together these nine simulations are called "SSTA_only."

An idealized simulation, named "2K_SSTA," in which a uniform warming of $2 \mathrm{~K}$ is added to the control SSTs throughout the integration is also conducted. The warming of $2 \mathrm{~K}$ is chosen because it approximates the average SSTA projected by the nine AOGCMs over the tropical and subtropical Atlantic and Indian Oceans. As in the SST_only simulations, the LBCs and $\mathrm{CO}_{2}$ concentration for the 2K_SSTA simulation are taken from 1981 to 2000 values.

A single simulation, named "CO2_only," is forced with the $\mathrm{CO}_{2}$ concentration for 2081-2100 (757 ppm) and driven with lateral boundary conditions and SSTs from 1981 to 2000. Therefore, this simulation isolates the radiative effects of $\mathrm{CO}_{2}$ increases within the regional model domain, excluding the effects of global $\mathrm{CO}_{2}$ increases and SST changes.

We conducted one simulation (LBCA_only_EC) in which only the LBCs are changed from the present day control simulation, using anomalous LBCs from the ECHAM model. This produced a climate state that is physically unrealistic because of inconsistencies between the lateral and surface boundary conditions. For this reason, the role of anomalous LBCs and SSTs are assessed together using a simulation named "SSTA + LBCA_EC" in which the 2081-2100 SSTAs and LBCAs derived from the ECHAM AOGCM are applied to the RCM, with $\mathrm{CO}_{2}$ prescribed at the 1981-2000 concentration.

Although soil moisture and temperature are not prescribed within the RCM, the relative importance of the initialization of these variables in the future simulations is of concern, especially since there is no consensus regarding the role of northern African land conditions in determining future climate in the region (Maynard and Royer 2004; Paeth and Thamm 2007; Moufouma-Okia and Rowell 2010; Paeth et al. 2009). In addition, land/atmosphere interactions are particularly strong over the Sahel (Xue and Shukla 1993, 1996; Koster et al. 2004), and our previous modeling experience suggests that soil moisture and temperature initialization can strongly impact the simulation of present day West African climate. We conduct a sensitivity simulation to evaluate the role of the initialization of soil variables in the fully forced future simulations. This simulation is designed to evaluate the impacts on the future precipitation predictions due to uncertainty in the twentyfirst century soil moisture and temperature. Uncertainty in the future soil variables may originate from, for example, rainfall anomalies during the winter and spring months at the end of the twenty-first century that may influence the soil conditions in March when the RCM simulations are initialized. For this simulation, named "21_DRY," the soil moisture and temperature at four levels are initialized from the March mean for 1983, 1990, 1998, and 2000 from the ECMWF ERA40 reanalysis (ECMWF 2002). These years are selected because they are the four driest March distributions during the 1981-2000 period. (Recall that for all other simulations, soil moisture and temperature are initialized from the 1981-2000 average of March.) SSTAs and LBCAs are derived from the ECHAM simulation, and the $\mathrm{CO}_{2}$ concentration is $757 \mathrm{ppm}$.

\section{Results}

Regional moisture budget analyses for the Sahel, Guinean Coast, and East African regions are examined below to relate precipitation and circulation anomalies, and improve our understanding of the processes of climate change in the 
(a)

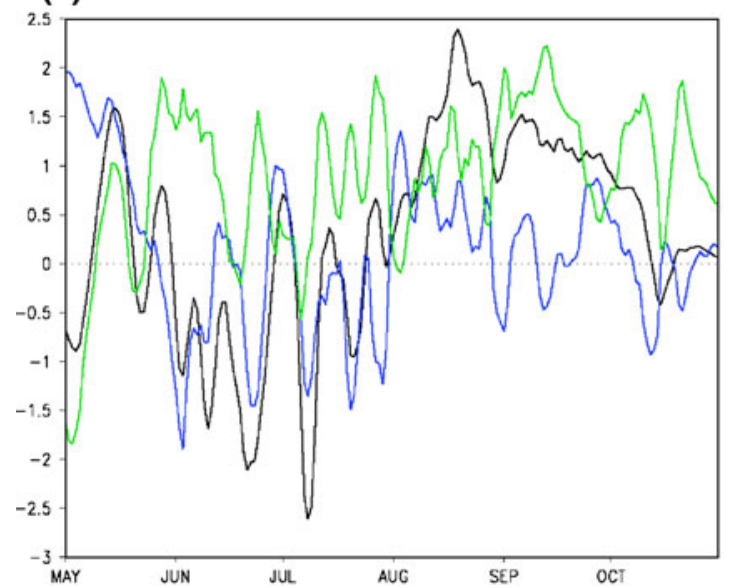

(c)

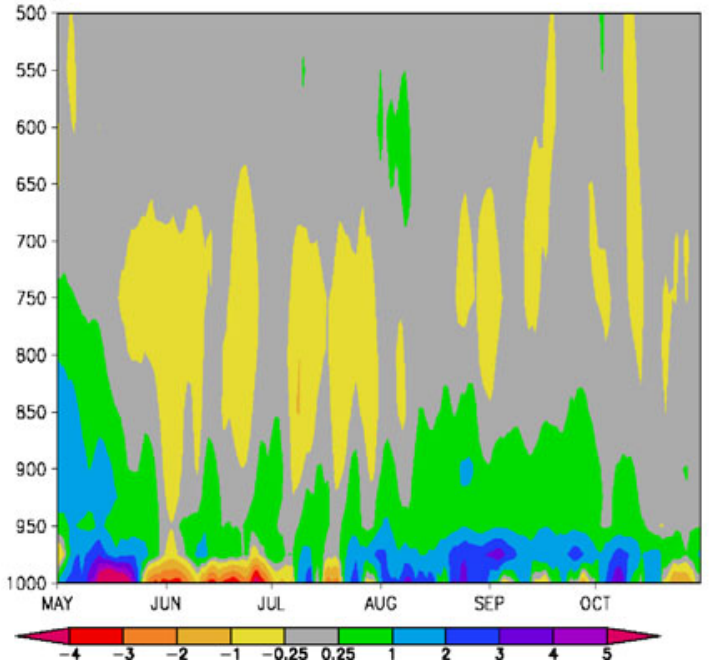

Fig. 3 The 5-day running mean of the area-averaged, ensemble averaged anomalies (2081-2100 minus 1981-2000) in a precipitation (black), vertically integrated zonal moisture convergence (blue) and meridional moisture convergence (green), b evaporation (red), and vertically integrated meridional moisture advection (orange) and zonal moisture advection (purple) from the fully forced RCM

projections. This analysis is followed by an examination of the role of the individual climate forcings and the sensitivity of the predictions to uncertainties in soil conditions, and an investigation of why the ensemble rainfall predictions are similar despite differences in the future climate forcings, specifically the SSTAs.

\subsection{Analysis of Sahel precipitation anomalies}

The terms of the moisture budget, including precipitation, evaporation, and vertically integrated meridional and zonal moisture convergence and advection, are plotted in Fig. 3a and $b$, as anomalies for the end of the twenty-first century, and area-averaged over the Sahel $\left(8^{\circ} \mathrm{N}-14^{\circ} \mathrm{N}\right.$ and $18^{\circ} \mathrm{W}-$ $18^{\circ} \mathrm{E}$; Fig. 2a). Monthly anomalies in the residual (b)

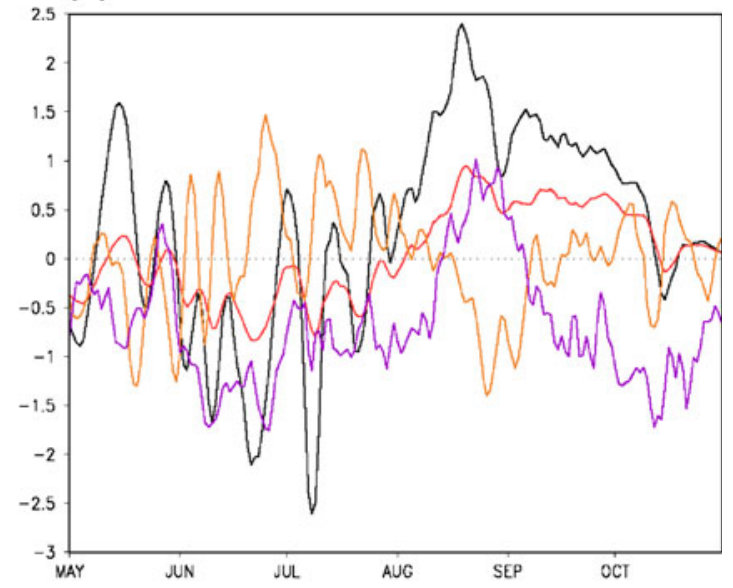

(d)

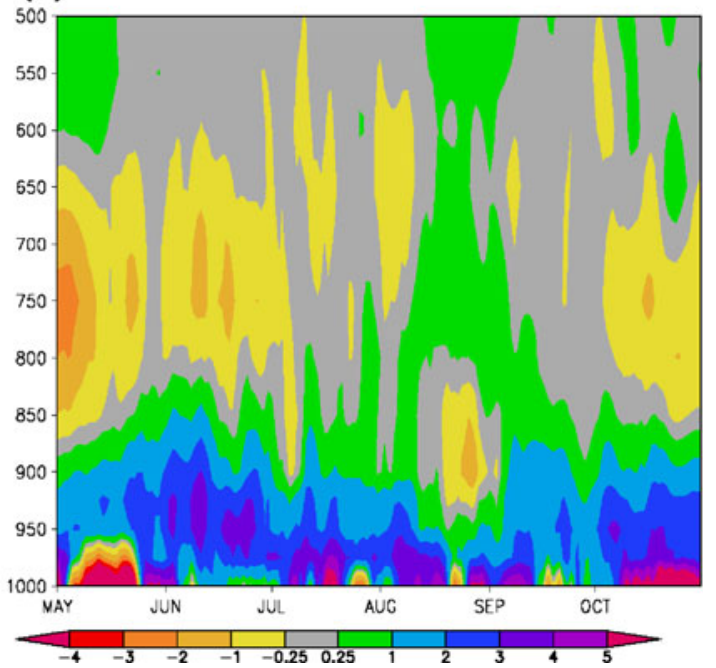

simulations for the Sahel. Units are mm/day. Vertical profiles of the 5-day running mean of the area-averaged, ensemble averaged anomalies (2081-2100 to 1981-2000) in c zonal and d meridional moisture convergence from the fully forced RCM simulations for the Sahel. Units are $\left(10^{-3} \mathrm{~m} \mathrm{~s}^{-2}\right)\left(\mathrm{kg}_{-} \mathrm{H}_{2} \mathrm{O}\right.$ kg_air $\left.{ }^{-1}\right)$

contribute relatively little to the anomalous moisture budget balance of the fully forced future climate, so are not considered further. Vertical profiles of the area-averaged zonal and meridional moisture convergence anomalies due to the full forcings (Fig. 3c, d, respectively) together with the vertically integrated moisture budget (Fig. 3a, b) enable a better understanding of the connections between precipitation and circulation changes by revealing which levels contribute to the moisture convergence anomalies.

During June and July, dry conditions of up to $-2.5 \mathrm{~mm} /$ day are accompanied by decreases in evaporation (Fig. 3b) reaching from 25 to up to $50 \%$ of the rainfall deficit and are supported by anomalous vertically integrated meridional moisture advection (Fig. 3b) and near-surface and mid-level zonal moisture divergence (Fig. 3a, c). These components of 
(a)

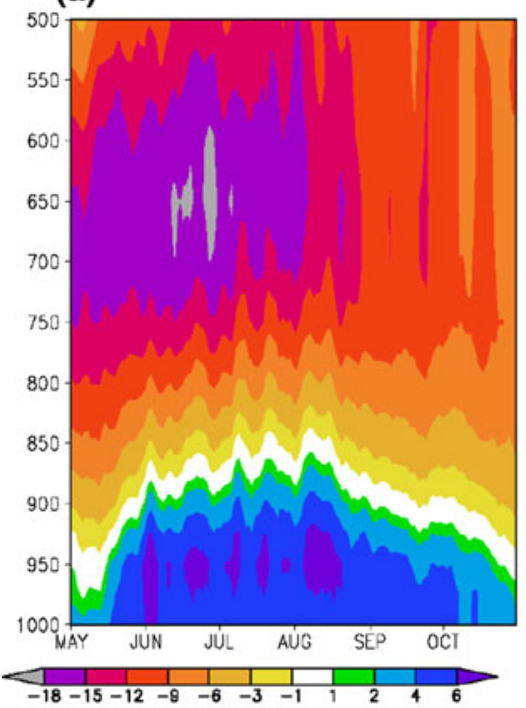

(d)

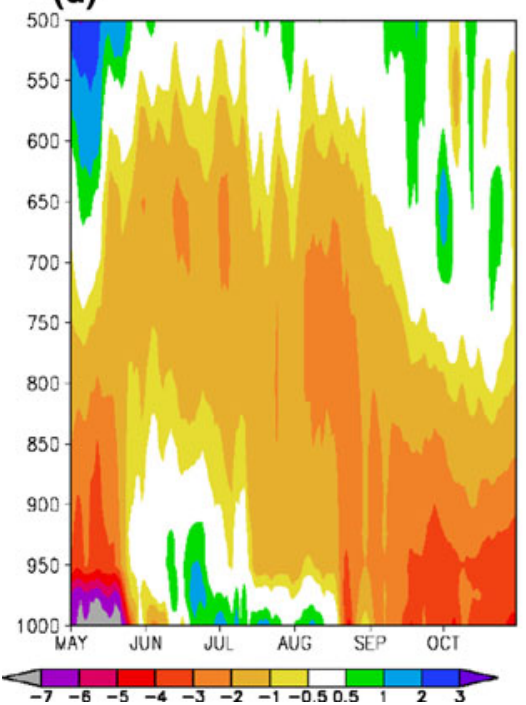

(b)

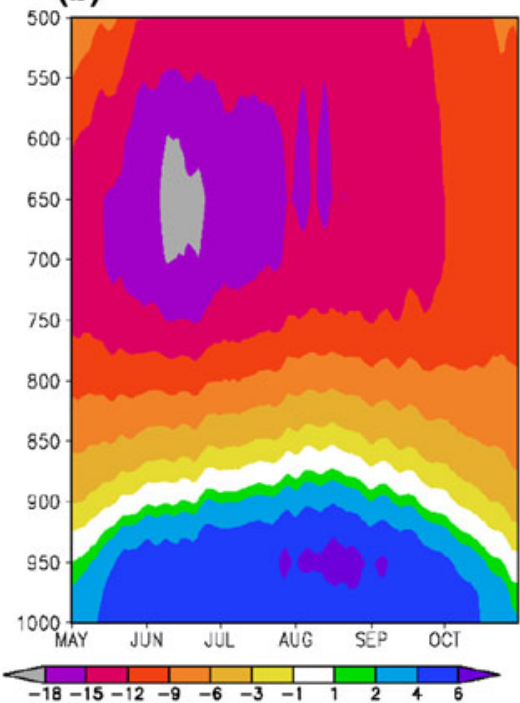

(e)

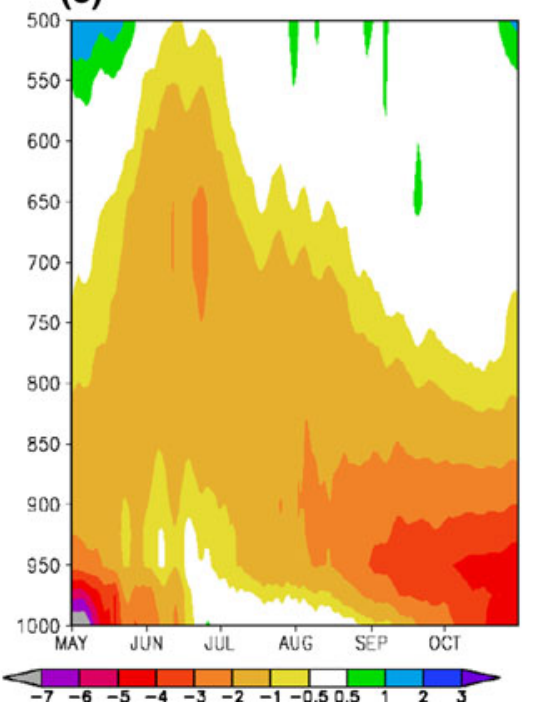

(c)
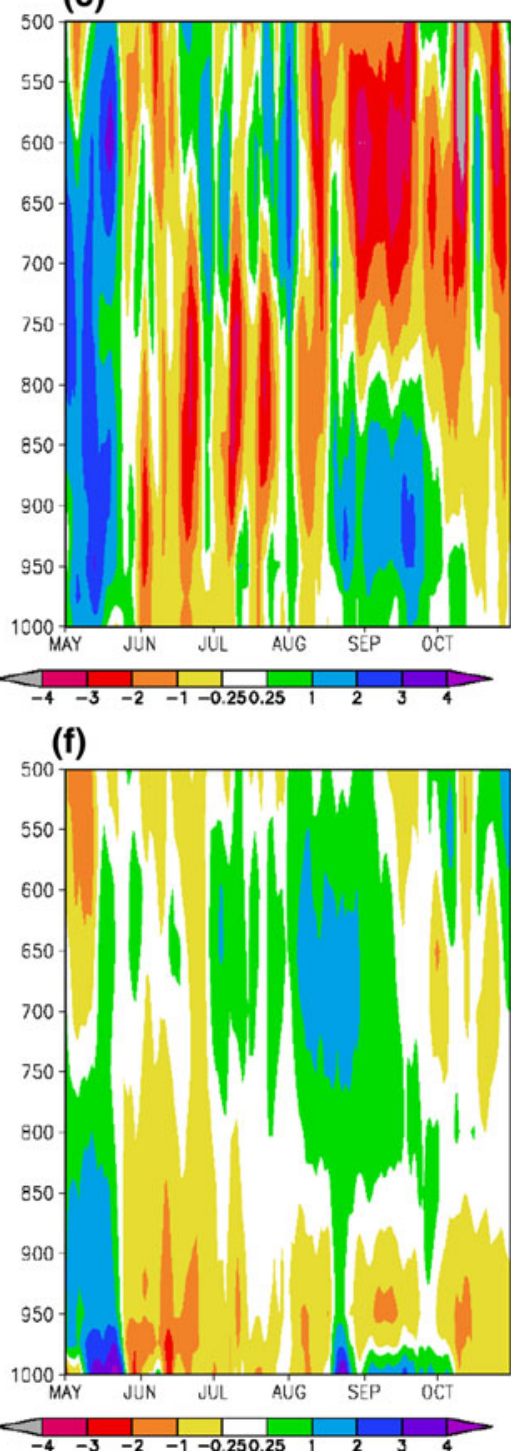

Fig. 4 The 5-day running mean of the zonal wind profiles at $18^{\circ} \mathrm{W}$, averaged over $8^{\circ} \mathrm{N}-14^{\circ} \mathrm{N}$ for the (a) control simulation, (b) ensemble average of the fully forced future simulations, and (c) difference (future: control). The 5-day running mean of the meridional wind

the moisture budget dominate the anomalous low-level meridional moisture convergence (Fig. 3a,d) and vertically integrated zonal moisture advection (Fig. 3b) that oppose the drying in June and July.

Cross sections of the zonal and meridional wind on the western and northern edge of the Sahel averaging region allow us to relate the changes in regional-scale moisture convergence to the larger-scale circulation and moisture fields. Profiles of the zonal wind averaged from $8^{\circ} \mathrm{N}$ to $14^{\circ} \mathrm{N}$ along the western edge of the Sahel region at $18^{\circ} \mathrm{W}$ from the control simulation, ensemble averaged fully forced future simulations, and the difference are shown in Fig. 4a-c. The control simulation (Fig. 4a) realistically places the WAWJ from the surface to $875 \mathrm{hPa}$, and the profiles at $16^{\circ} \mathrm{N}$, averaged over $18^{\circ} \mathrm{W}-18^{\circ} \mathrm{E}$ for the (d) control simulation, (e) ensemble average of the fully forced future simulations, and (f) difference (future minus control). Units are $\mathrm{m} \mathrm{s}^{-1}$

AEJ is centered near $650 \mathrm{hPa}$. A weaker WAWJ and an AEJ that is stronger below the core (Fig. $4 b, c)$ support anomalous zonal moisture divergence in the future simulation during June and July. This relationship among a strong AEJ, weak WAWJ, and drying is similar to observed present day variability.

During August through mid-October wetter conditions of up to $2.5 \mathrm{~mm} /$ day are predicted for the Sahel region (Fig. 3a) and are supported by increased evaporation reaching from 33 to $50 \%$ of the rainfall anomaly, meridional moisture advection in late-August (Fig. 3b), and anomalous low-level zonal moisture convergence in August and weakly in September (Fig. 3a, c). A more detailed understanding of the circulation and moisture 
(a)

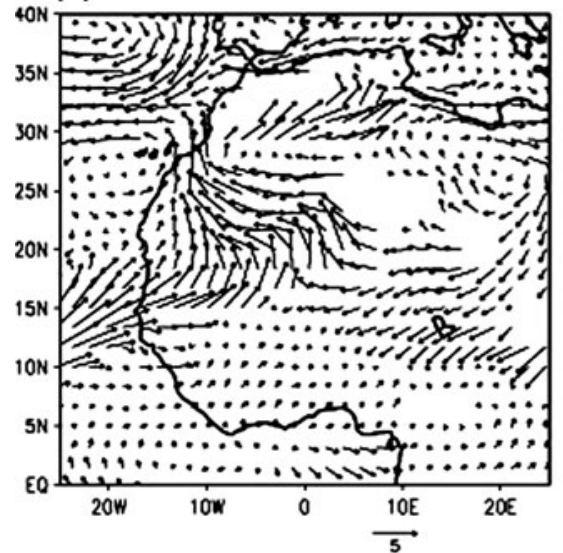

(d)

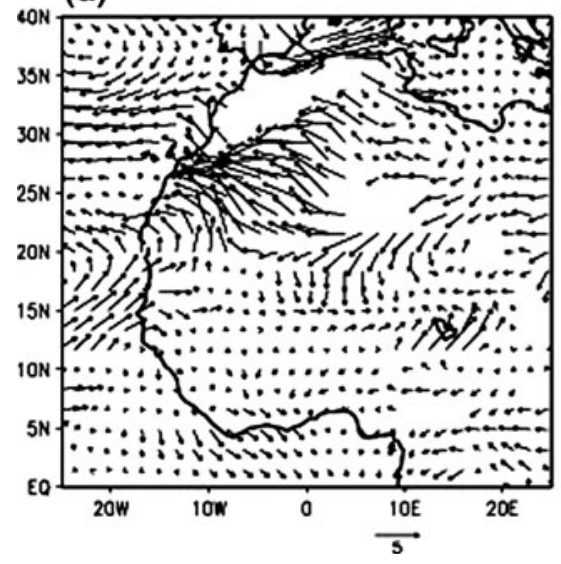

(b)

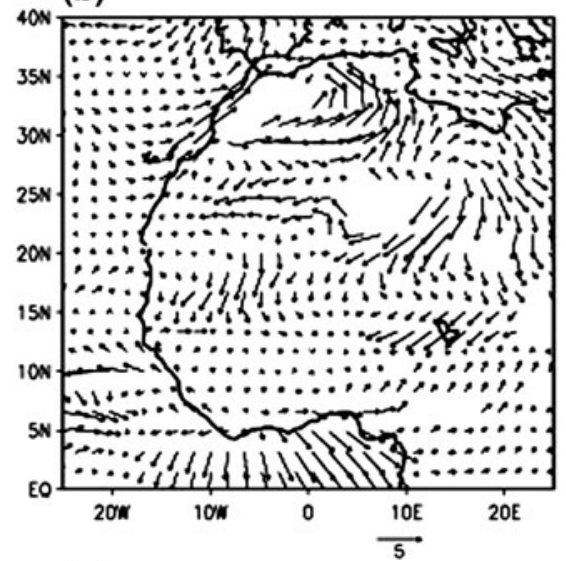

(e)

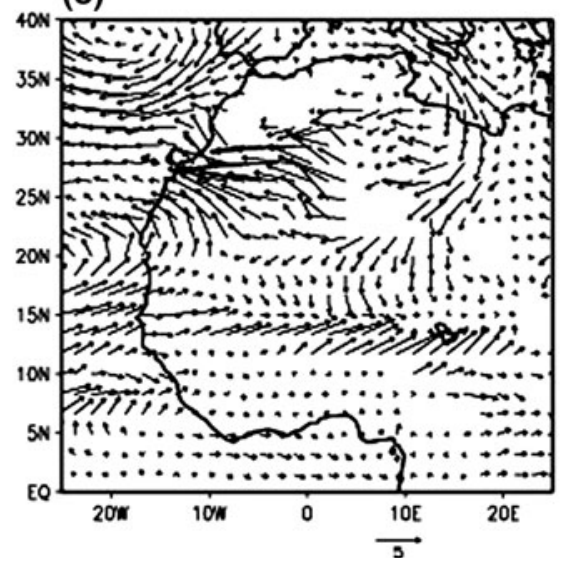

(c)

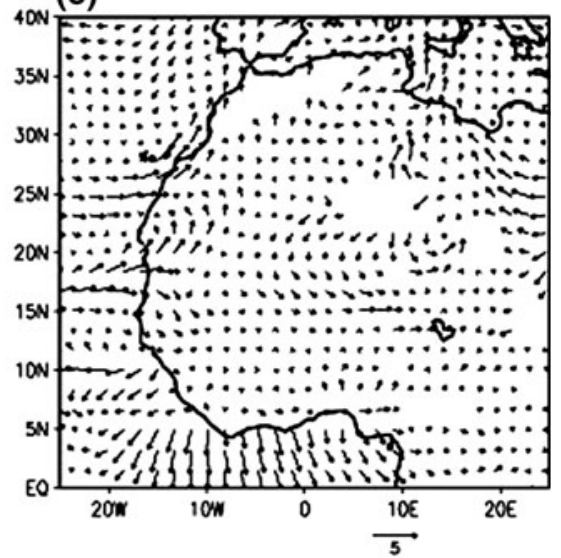

(f)

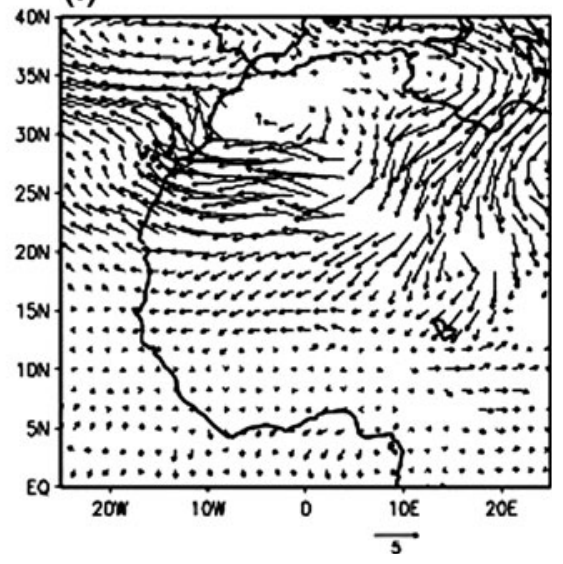

Fig. 5 Ensemble averaged wind (m/s) anomalies (2081-2100 minus 1981-2000) at $925 \mathrm{hPa}$ for a May, b June, c July, d August, e September, and $\mathbf{f}$ October from the fully forced future simulations

anomalies that support the changes in the moisture budget is enabled by comparing the monthly wind anomalies at $925 \mathrm{hPa}$ for the future (Fig. 5) and the anomalous water vapor mixing ratio (shaded) and moisture transport vectors (i.e., the horizontal wind scaled by the water vapor mixing ratio) at $925 \mathrm{hPa}$ (Fig. 6). In mid-August through September the anomalous low-level zonal moisture convergence is related to a stronger WAWJ, especially north of $12^{\circ} \mathrm{N}$ (Fig. $5 \mathrm{~d}$, e), that is slightly deeper (Fig. $4 \mathrm{a}-\mathrm{c}$ ). South of $12^{\circ} \mathrm{N}$, changes in the jet are weaker (Fig. $5 \mathrm{~d}$, e), but an increase in the moisture transport is achieved by a higher water vapor mixing ratio carried by the jet in the future (Fig. 6d, e), which contributes to the anomalous zonal moisture convergence. Anomalous meridional moisture convergence contributes up to $2 \mathrm{~mm} / \mathrm{day}$ (Fig. 3a), primarily at low-levels (Fig. 3d), and is supported by stronger low-level northerly flow near the northern edge of the Sahel region box as shown in Fig. 4d$\mathrm{f}$, which display the meridional wind at $16^{\circ} \mathrm{N}$ averaged from $18^{\circ} \mathrm{W}$ to $18^{\circ} \mathrm{E}$ for the control simulation, the ensemble average of the future simulations, and the difference, respectively. The strengthened low-level northerly flow in September and October originates from the Mediterranean region (Fig. 5e, f) and supports the connection between Mediterranean SSTAs and Sahel rainfall anomalies discussed in Sect. 4.4. The simulated wetter Sahel, stronger WAWJ, and enhanced moisture transport from the Mediterranean (Fig. 6e, f) are also consistent with patterns observed in present day climate variability (Rowell 2003).

\subsection{Analysis of Guinean Coast precipitation anomalies}

Figure 7 is similar to Fig. 3 and shows the terms of the atmospheric moisture budget as anomalies for the future over the Guinean Coast region $\left(4^{\circ} \mathrm{N}-7.5^{\circ} \mathrm{N}\right.$ and $18^{\circ} \mathrm{W}-$ $10^{\circ} \mathrm{E}$; Fig. 2a). The model predicts an anomalous monthly precipitation cycle for the end of the twenty-first century over the Guinean Coast (Fig. 7a) that is similar to, but stronger than, that of the Sahel (Fig. 3a). Anomalies in vertically integrated zonal and meridional moisture convergence emerge as the dominant terms of the moisture budget for the fully forced future climate over the Guinean Coast region and relate strongly to the predicted precipitation increases in May and August to October and 
(a)

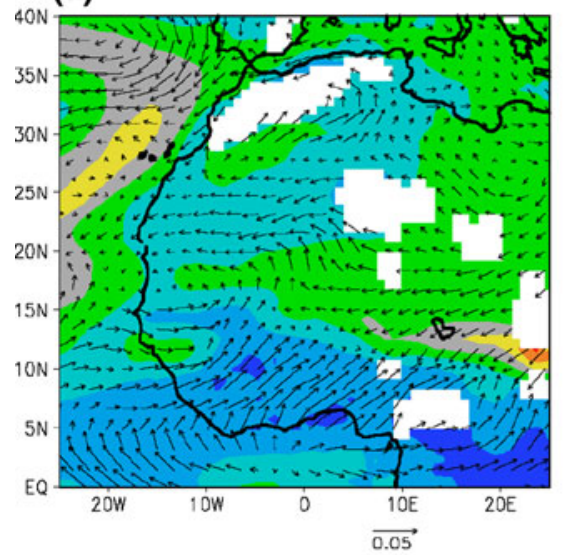

(d)

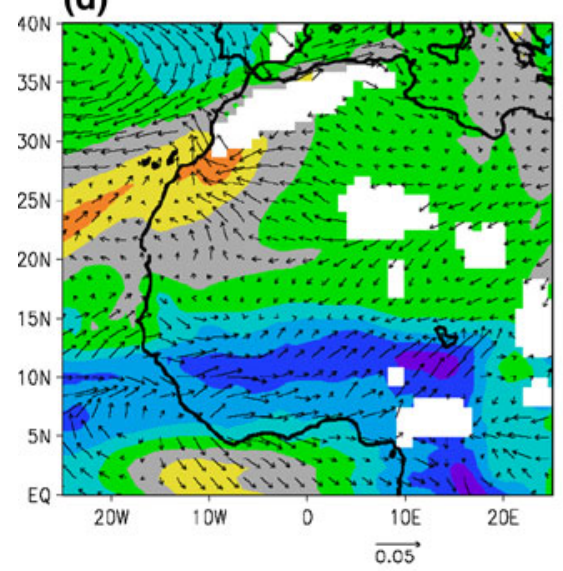

(b)

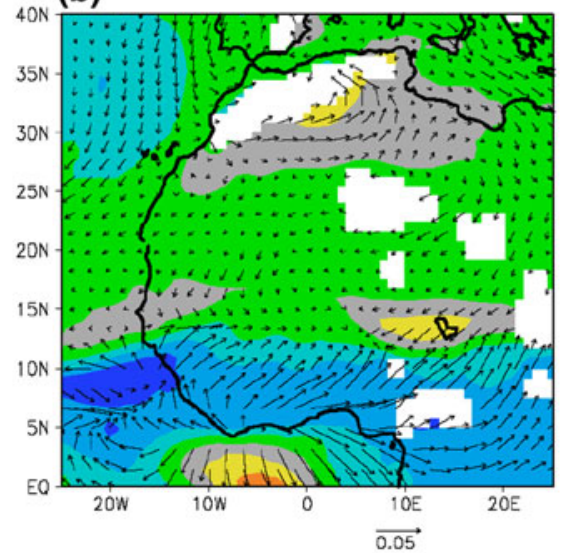

(e)

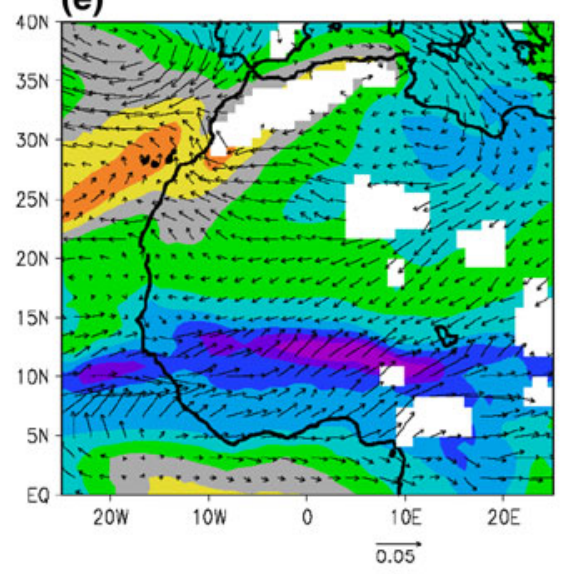

(c)

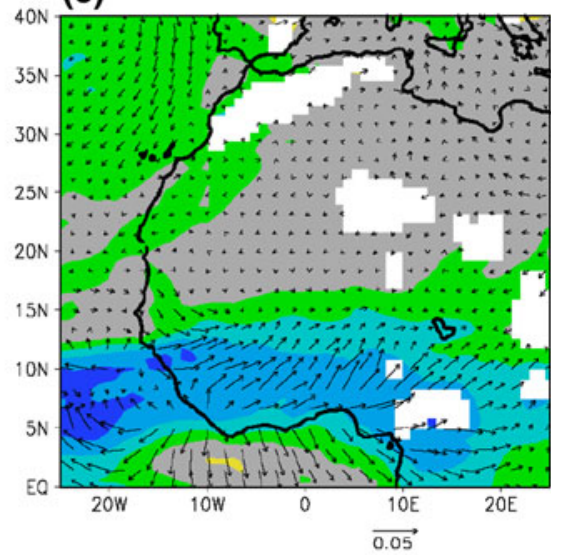

(f)

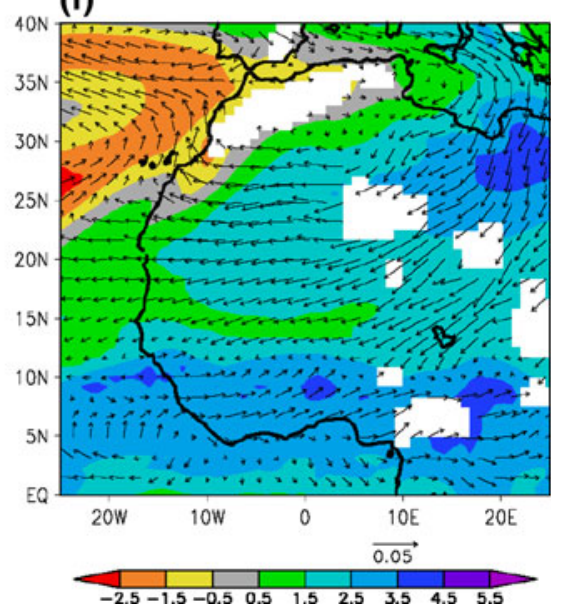

Fig. 6 Ensemble averaged anomalies (2081-2100 minus 1981-2000) in water vapor mixing ratio $(\mathrm{kg} / \mathrm{kg}$, shaded $)$ and moisture transport $\left(\mathrm{kg}_{-} \mathrm{H}_{2} \mathrm{O} \mathrm{kg} \_a \mathrm{ir}^{-1}\right)\left(\mathrm{m} \mathrm{s}^{-1}\right)$, vectors at $925 \mathrm{hPa}$ for a May, b June,

decreases in July to August (Fig. 7a). Unlike the response in the Sahel (Fig. 3b), contributions from evaporation and vertically integrated moisture advection anomalies are relatively small over the Guinean Coast from May through October (Fig. 7b).

The wet period over the Guinean Coast in May, with anomalies reaching nearly $7 \mathrm{~mm} / \mathrm{day}$, is supported by anomalous zonal moisture convergence (Fig. 7a) that extends from the surface to $550 \mathrm{hPa}$ (Fig. 7c) as well as anomalous meridional moisture convergence (Fig. 7a) at low-and mid-levels (Fig. 7d).

In order to better understand the zonal moisture convergence anomalies, we consider profiles of the zonal wind averaged from $4^{\circ} \mathrm{N}$ to $7.5^{\circ} \mathrm{N}$ along the western edge of the Guinean Coast region at $18^{\circ} \mathrm{W}$ from the control and future simulations, and the difference (Fig. 8a-c). The anomalous zonal moisture convergence that supports wetter conditions along the Guinean Coast region in late May is related to zonal wind anomalies along the west coast of Africa. Figure $8 \mathrm{~d}-\mathrm{f}$ show the meridional wind averaged from c July, d August, e September, and f October from the fully forced future simulations

$18^{\circ} \mathrm{W}$ to $10^{\circ} \mathrm{E}$ along the southern edge of the Guinean Coast region at $4^{\circ} \mathrm{N}$ for the control simulation, ensemble averaged fully forced future simulations, and the difference. Although the southerly monsoon flow from the surface to about $850 \mathrm{hPa}$ (Fig. 8d) is one of the primary sources of moisture for the West African monsoon, in early May the anomalous meridional moisture convergence in the future is not related to a strong change in this monsoon flow (Fig. 8f). These cross sections suggest that while the anomalies in meridional wind contribute weakly to the anomalous moisture convergence over the Guinean Coast region in May, increases in atmospheric moisture play a significant role.

The importance of atmospheric moisture anomalies in supporting the future precipitation anomalies is confirmed by comparison of Figs. 5 and 6, which show the anomalous wind and moisture transport vectors, respectively, at $925 \mathrm{hPa}$. In May, despite weak anomalies in the southerly monsoon flow (Fig. 5a), there is increased moisture transport onto the continent related to positive atmospheric 
(a)

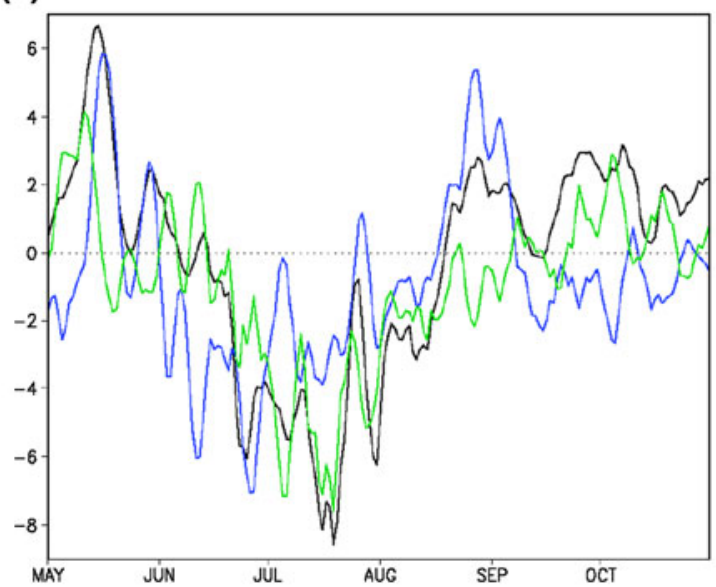

(c)

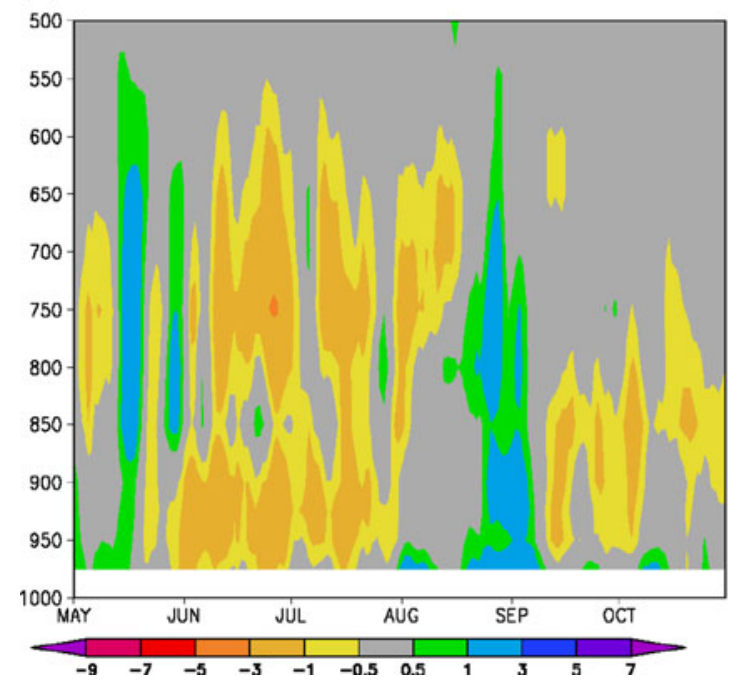

Fig. 7 The 5-day running mean of the area-averaged, ensemble averaged anomalies (2081-2100 minus 1981-2000) in a precipitation (black), vertically integrated zonal moisture convergence (blue) and meridional moisture convergence (green), b evaporation (red), and vertically integrated meridional moisture advection (orange) and zonal moisture advection (purple) from the fully forced RCM

moisture anomalies in the future over the Gulf of Guinea (Fig. 6a). The increased moisture transport into the Guinean Coast region at $925 \mathrm{hPa}$ in the future supports the lowlevel meridional convergence anomalies (Fig. 7d) that contribute to enhanced rainfall in the future.

From June through mid-August, future precipitation decreases over the Guinean Coast region (Fig. 7a) reach close to $-9 \mathrm{~mm} /$ day. Recall from PC10, that in July and August the precipitation in the control simulation has a southward bias, with too much (little) rainfall over the Guinean Coast (Sahel). One possibility is that the rainfall predictions over the Guinean Coast region during those months may apply to the Sahel, and comparison with other modeling studies would be useful to provide support for or against this interpretation. The negative precipitation (b)

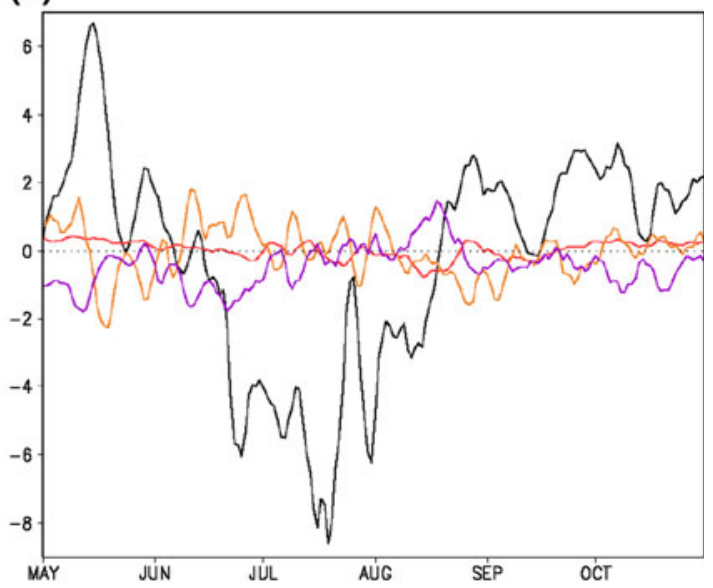

(d)

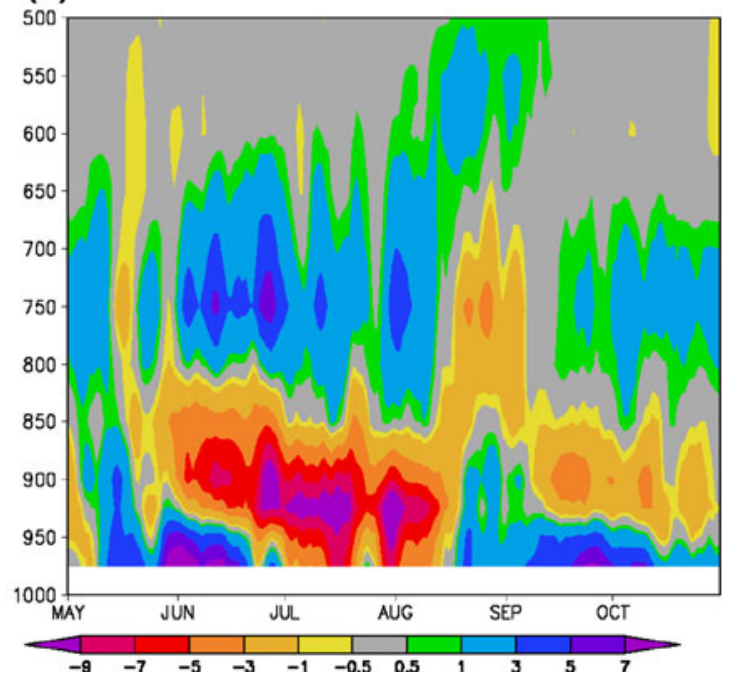

simulations for the Guinean Coast region. Units are $\mathrm{mm} /$ day. Vertical profiles of the 5-day running mean of the area-averaged, ensemble averaged anomalies (2081-2100 to 1981-2000) in c zonal and d meridional moisture convergence from the fully forced RCM simulations for the Guinean Coast region. Units are $\left(10^{-3} \mathrm{~m} \mathrm{~s}^{-2}\right)$ $\left(\mathrm{kg} \_\mathrm{H}_{2} \mathrm{O} \mathrm{kg \_ air}{ }^{-1}\right)$

anomalies in June through mid-August are supported by anomalous low- and mid-level zonal (Fig. 7c) and lowlevel meridional (Fig. 7d) moisture divergence. The anomalous zonal moisture divergence is related to both a weakening of the low-level westerlies and strengthening of the mid-level easterlies along the west coast of Africa (Fig. 8a-c), while the anomalous low-level meridional divergence (Fig. 7d) is related to a weaker and more shallow southerly monsoon flow (Fig. 8d-f). The drier summertime conditions over the Guinean Coast region are related primarily to circulation changes, not atmospheric moisture anomalies (Figs. 5b, c and 6b, c).

Projected conditions are wetter in the future over the Guinean Coast region from mid-August through October. From mid-August through early September, these 
(a)

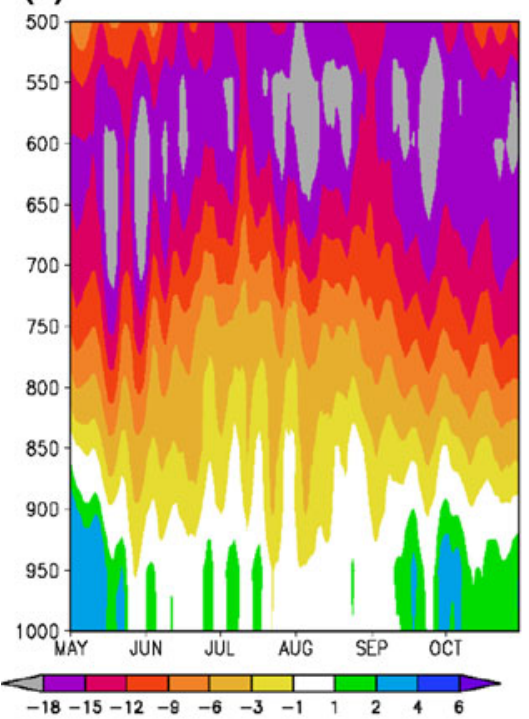

(d)

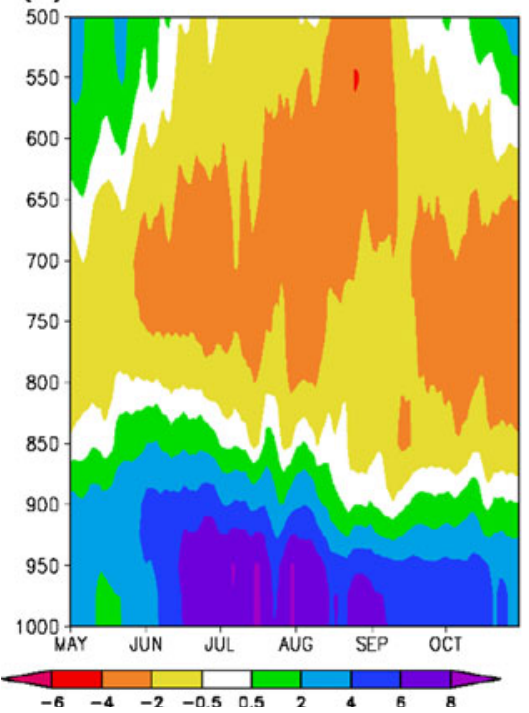

(b)

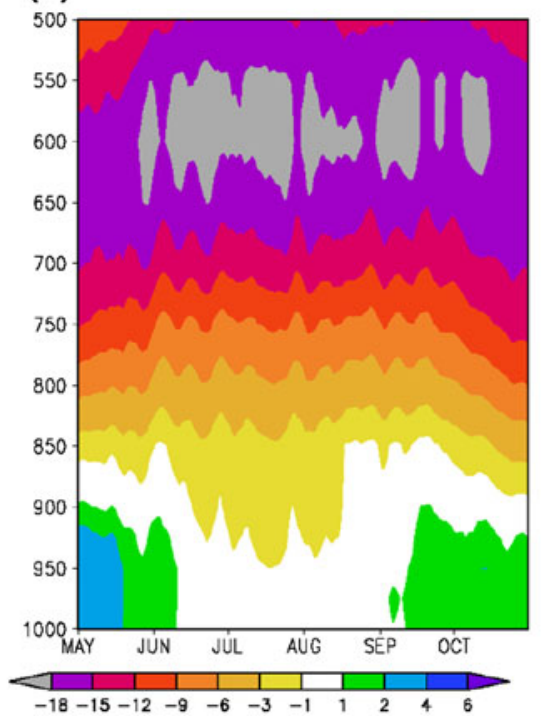

(e)

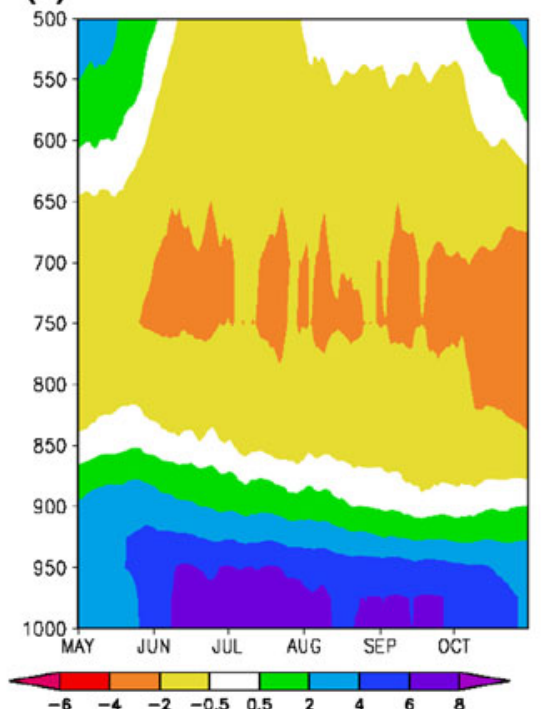

(c)

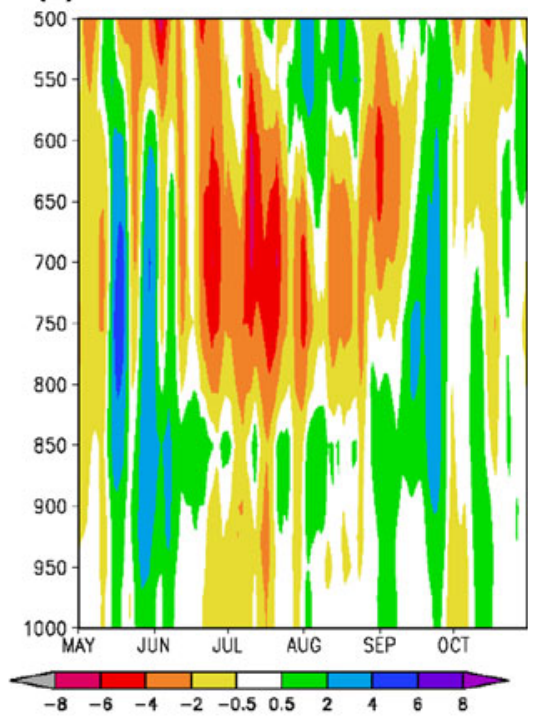

(f)

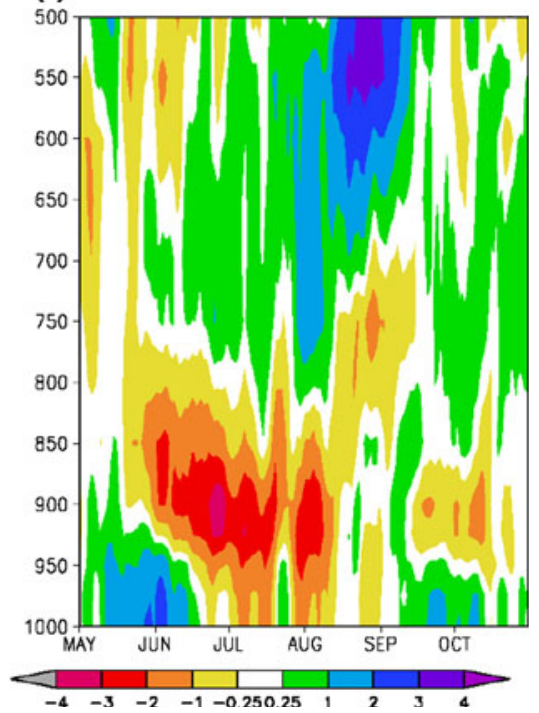

Fig. 8 The 5-day running mean of the zonal wind profiles at $18^{\circ} \mathrm{W}$, averaged over $4^{\circ} \mathrm{N}-7.5^{\circ} \mathrm{N}$ for the (a) control simulation, (b) ensemble average of the fully forced future simulations, and (c) difference (future: control). The 5-day running mean of the meridional wind profiles at $4^{\circ} \mathrm{N}$, averaged over $18^{\circ} \mathrm{W}-10^{\circ} \mathrm{E}$ for the (d) control simulation, (e) ensemble average of the fully forced future simulations, and (f) difference (future minus control). Units are $\mathrm{m} \mathrm{s}^{-1}$

\subsection{Analysis of East African precipitation anomalies}

Precipitation predictions for the end of the twenty-first century over the region in East Africa $\left(2^{\circ} \mathrm{S}-10^{\circ} \mathrm{N}\right.$ and $28^{\circ} \mathrm{E}-36^{\circ} \mathrm{E}$; Fig. 2a) covering parts of Uganda and Kenya are relatively weak except for a severe dry period peaking at a deficit of $10 \mathrm{~mm} /$ day in August and September (Fig. 9a). The decline in rainfall is triggered by anomalous meridional moisture divergence (Fig. 9a), and the drier conditions are sustained by anomalous zonal moisture divergence (Fig. 9a) and decreased evaporation of up to $-3.75 \mathrm{~mm} /$ day (Fig. 9b). Changes in the advection terms are insignificant (Fig. 9b). 
(a)

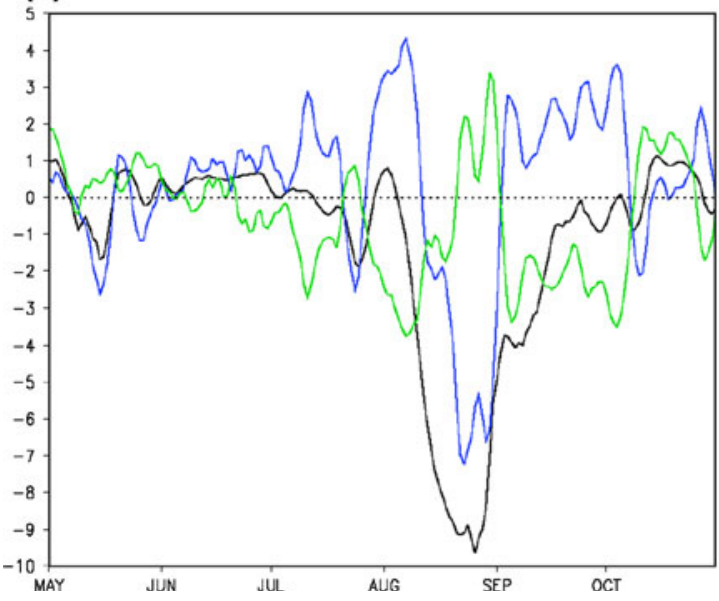

Fig. 9 The 5-day running mean of the area-averaged, ensemble averaged anomalies (2081-2100 minus 1981-2000) in a precipitation (black), vertically integrated zonal moisture convergence (blue) and meridional moisture convergence (green), b evaporation (red), and

The development of the late summer drought is associated with changes in the Somali jet, Turkana jet, and Indian monsoon. Figure 10 shows geopotential height and wind vectors at $900 \mathrm{hPa}$ averaged over August and September for the control simulation, the ensemble average of the fully forced future simulations, and the difference. The Somali jet, which is characterized by low-level southerly flow over the Horn of Africa that turns westerly over the Arabian Sea, is represented well in the control simulation. During August and September in the future, the Somali jet is much weaker with stronger flow diverting into the Turkana jet, similar to the modeled relationship in Vizy and Cook (2003). The dry conditions and strengthened Turkana jet are also similar to the present day relationship simulated by Sun et al. (1999). The weakened Indian monsoon, which is simulated adequately by the regional model (not shown), and dry conditions in East Africa are also similar to observed present-day relationships (Camberlin 1997). The simulated climate changes that are consistent with present day climate variability and the reasonable regional model simulation of the control summer Indian rainfall both lend support to the confidence in the rainfall predictions over East Africa. Still, we note that any inaccuracies in the simulation of the present day or future Indian monsoon may have a strong impact on the future predictions over East Africa given the strong connections observed between these two regions in the present day climate.

\subsection{Individual climate forcings}

In this section we discuss the impact of uncertainty in soil moisture and temperature initialization on the predictions (b)

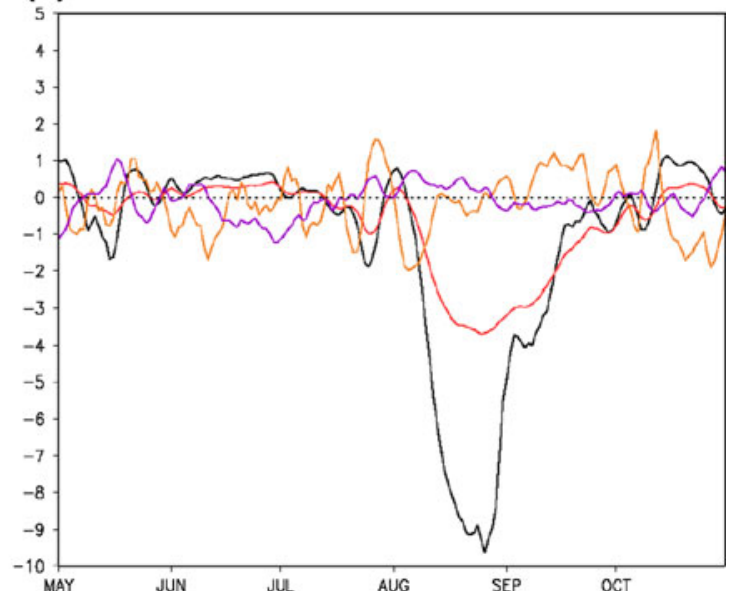

vertically integrated meridional moisture advection (orange) and zonal moisture advection (purple) from the fully forced RCM simulations for the East African region. Units are $\mathrm{mm} / \mathrm{day}$

and investigate the role of individual climate forcings, including atmospheric $\mathrm{CO}_{2}$ concentration and SST and LBC anomalies. The purpose is to add confidence to the projections presented in $\mathrm{PC} 10$ by improving our understanding of the important climate change processes.

The strength of feedbacks between the land-surface and the atmosphere over the Sahel, together with the uncertainty in future soil temperature and moisture fields calls for a sensitivity test to assess the impact of this uncertainty on the future climate predictions. Precipitation anomalies from the nine fully forced future simulations and the 21_DRY simulation for the Guinean Coast and Sahel regions are shown in Fig. $2 b$ and c. For both regions and for all months, precipitation anomalies from the 21_DRY simulation (red dot) are within the range of the fully forced future precipitation anomalies that were initialized with climatological soil conditions (black diamonds and blue dot). The results from this sensitivity test illustrate that the uncertainty introduced into the future rainfall predictions due to uncertainties in soil moisture and temperature initialization is small compared to the uncertainty due to differences in the details of the SST and LBC forcings. We note that in addition to the uncertainties in future soil moisture and temperature, which we have tested here, there are also uncertainties in future changes in soil type, which may be due to natural processes, land-use practices, or both. It is possible that the associated changes in soil characteristics, for example, water holding capacity, may be important in future predictions.

In order to isolate the role of SSTAs and LBCAs, we compare the monthly precipitation anomalies due to SSTA, LBCA and $\mathrm{CO}_{2}$ forcing (Fig. 11a-c) with those due to only SSTA and LBCA forcing (Fig. 11d-f). For both 
(a)

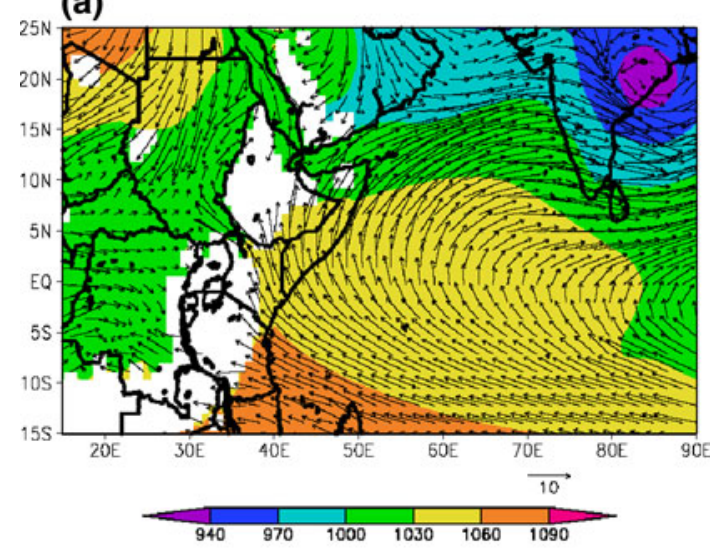

(b)

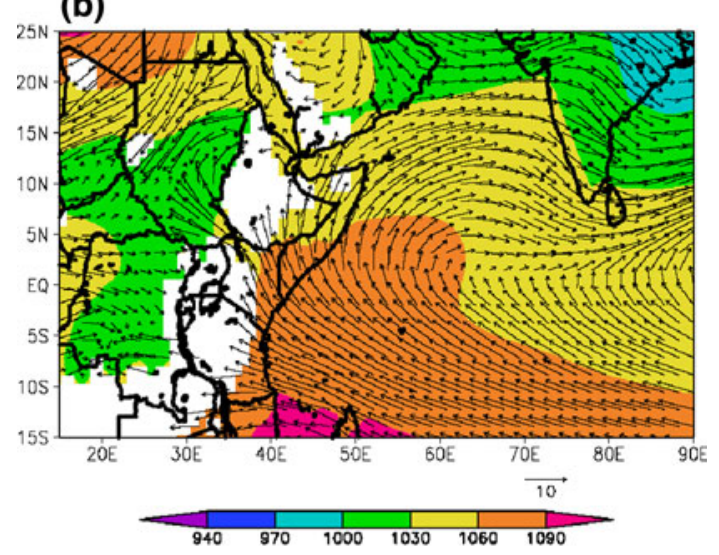

(c)

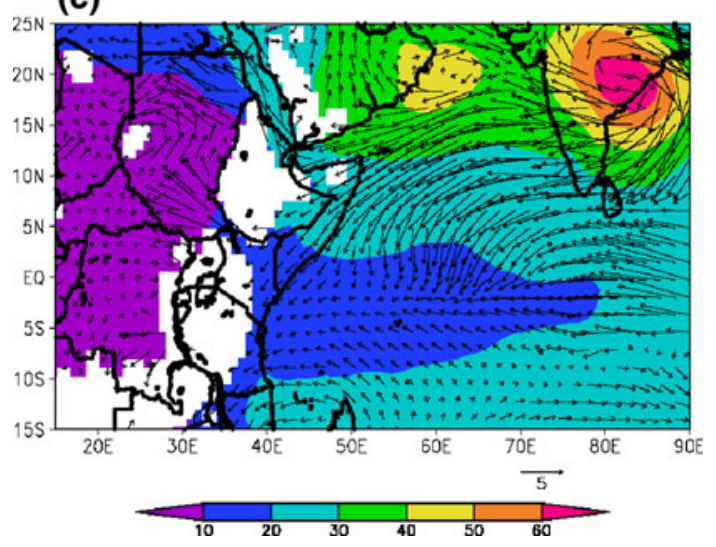

Fig. 10 Geopotential heights ( $\mathrm{m}$, shaded) and wind ( $\mathrm{m} / \mathrm{s}$, vectors) at $900 \mathrm{hPa}$ during August and September from the (a) control simulation, (b) ensemble average of the fully forced future simulations, and (c) difference (future minus control)

simulations, SSTA and LBCA forcings are provided by the ECHAM AOGCM. The distributions of the precipitation anomalies forced by SSTAs and LBCAs are very similar with and without regional $\mathrm{CO}_{2}$ forcing from May through October (May, September, and October not shown). For example, drying is produced in the Gulf of Guinea and central Africa is wetter in June, central Africa and the
Guinean Coast are drier in July, and the Sahel (East Africa) is wetter (drier) in August both with (Fig. 11a-c, respectively) and without (Fig. 11d-f, respectively) the regional $\mathrm{CO}_{2}$ forcing. This agreement indicates that the fully forced twenty-first century rainfall anomalies (Fig. 1 and PC10) are primarily caused by SST and lateral boundary forcing that are consequences of the global $\mathrm{CO}_{2}$ forcing, and not the regional $\mathrm{CO}_{2}$ forcing applied within the $\mathrm{RCM}$ domain.

However, regional $\mathrm{CO}_{2}$ forcing does play an important role in some regions. The full forcing produces precipitation anomalies that are near zero or weakly negative over the Sahel region in June (Fig. 11a), while the SSTA and LBCA forcing results in strong drying over the Sahel (Fig. 11d). In July and August, Sahelian precipitation anomalies are strongly positive (weakly positive) due to SSTA and LBCA forcing with (Fig. 11b, c) and without (Fig. 11e, f) regional $\mathrm{CO}_{2}$ forcing. While the spatial distribution of the fully forced future precipitation anomalies is dominated by the SSTAs and LBCAs, regional $\mathrm{CO}_{2}$ forcing significantly impacts the magnitude of the rainfall anomalies, especially in the Sahel region, and generally produces more positive rainfall anomalies.

Figure 12 shows monthly precipitation anomalies due to increasing the $\mathrm{CO}_{2}$ concentration over the regional model domain from $330 \mathrm{ppm}$, as in the control simulation, to $757 \mathrm{ppm}$. Wetter conditions over the Sahel from May through September, with little change in October, are produced by these regional $\mathrm{CO}_{2}$ increases. The wet conditions are concentrated over the western Sahel in May and June (Fig. 12a, b), but extend across the continent in July, August, and September (Fig. 12c-e). Over the Guinean Coast region, regional $\mathrm{CO}_{2}$ forcing produces wetter conditions throughout the summer except for a dry period in July and August. In East Africa, regional $\mathrm{CO}_{2}$ forcing produces wetter conditions over western Ethiopia from May through September except for a small region of drying in June. In October conditions are wet (dry) over southern (northern) Ethiopia. The rainfall signal is weak over central Africa except in August when anomalies are positive (negative) over the Congo region (Uganda and southern Sudan) and in October when conditions are wetter.

The evolution of the land-surface warming over northern Africa from May through October due to regional $\mathrm{CO}_{2}$ forcing provides further insight to the Sahelian and Guinean Coast precipitation anomalies. Figure 13 shows monthly anomalies in surface temperature and moisture transport at $950 \mathrm{hPa}$ due to regional $\mathrm{CO}_{2}$ forcing. Warming is centered over the Sahara and peaks in July, while cooling related to increased rainfall occurs south of $15^{\circ} \mathrm{N}$ and peaks in August. In association with the Saharan warming, the low-level thermal low over northern Africa is intensified (not shown), and the anomalous cyclonic circulation carries moisture deeper into the continent. In May and June 
(a)

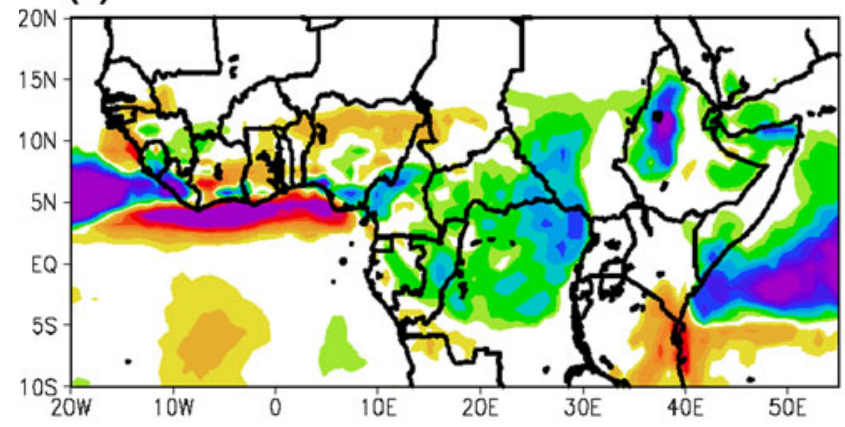

(b)

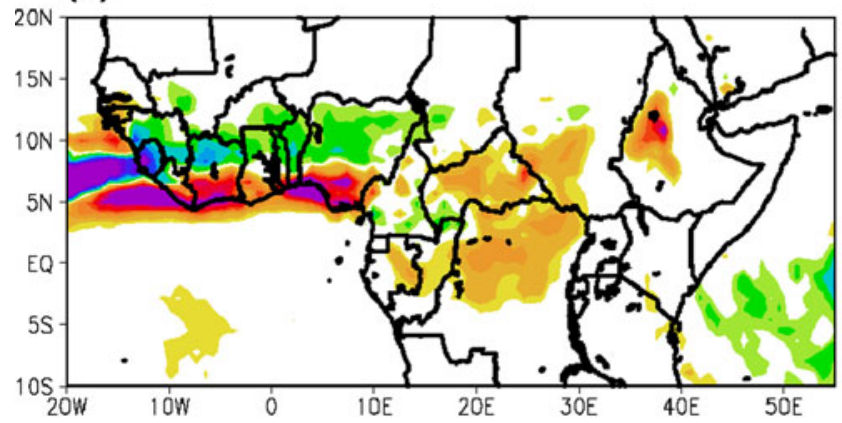

(c)

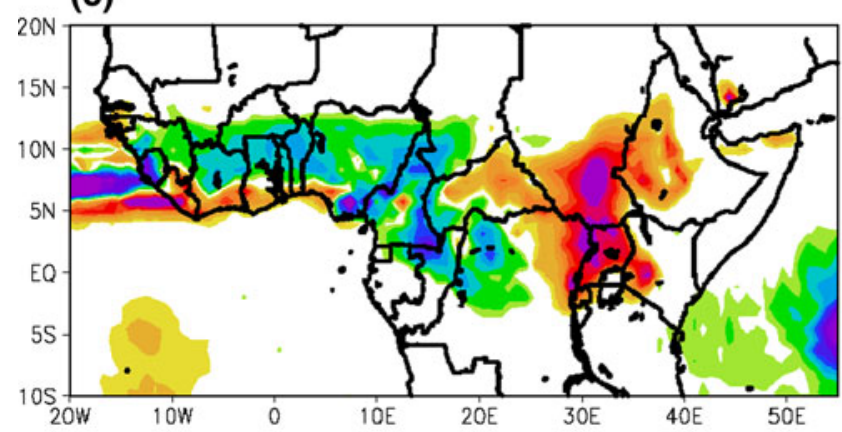

Fig. 11 Precipitation anomalies from the fully forced future simulation driven with anomalies from the ECHAM AOGCM for (a) June, (b) July, and (c) August, and from the SSTA + LBCA_EC

(Fig. 13a, b) this intensification is relatively weak, and so the additional moisture reaches only the Guinean Coast region and supports wetter conditions there. By July and August (Fig. 13c, d) the intensification of the thermal low peaks in association with the maximum Sahelian surface temperature anomalies, and the anomalous circulation transports moisture much deeper into the continent, supporting the wetter conditions over the Sahel instead of the Guinean Coast region, where higher pressure has developed. Although the Sahel is wetter in August due to both regional $\mathrm{CO}_{2}$ forcing alone and the full future forcings, distinctly different physical processes are working in each case, both of which have analogies in present day observed variability. (d)

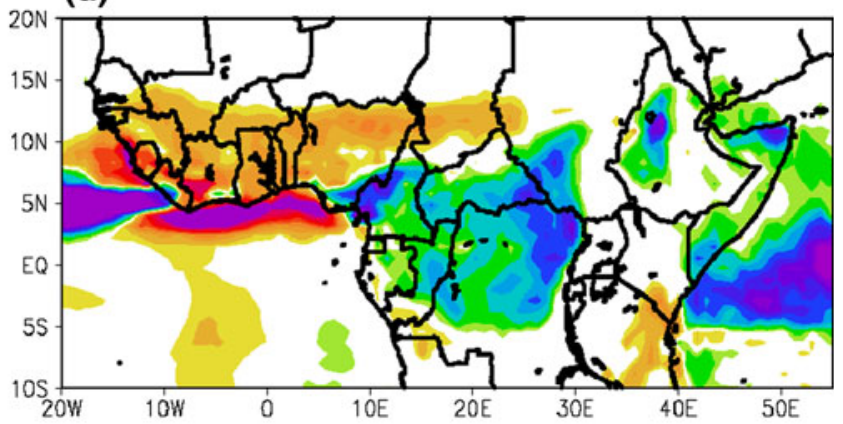

(e)

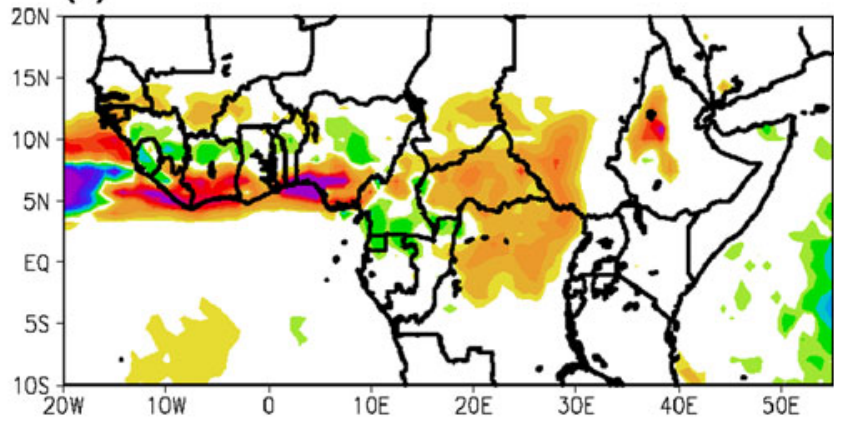

(f)

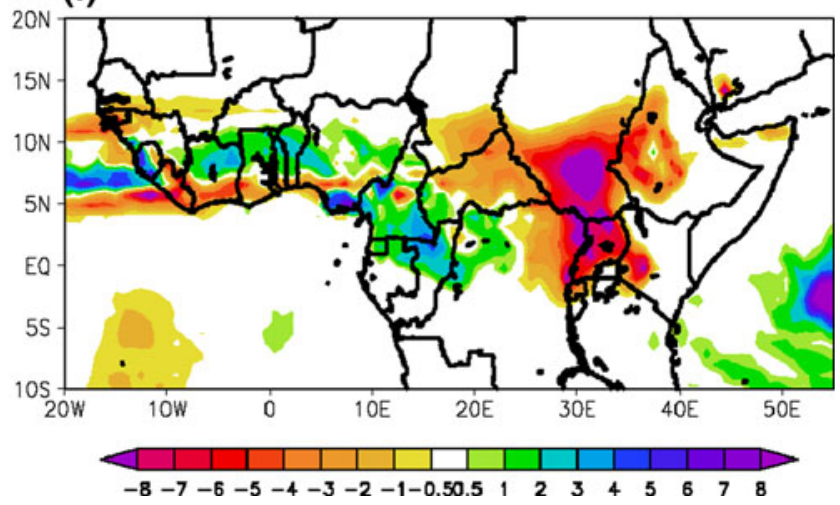

simulation, which does not include regional $\mathrm{CO}_{2}$ forcing, for (d) June, (e) July, and (f) August. Units are $\mathrm{mm} /$ day

During July and August, the peak of the wetter conditions over western Ethiopia in East Africa, anomalous southwesterly winds on the southeastern side of the thermal low flow into the topography of the Ethiopian Highlands supporting increased orographic rainfall. At the same time the Somali jet is stronger and the Turkana jet is weaker, similar to the modeled relationship in Vizy and Cook (2003).

The nine fully forced regional model ensemble members produce precipitation predictions (Fig. 1) that are consistent over much of sub-Saharan northern Africa. This ensemble agreement is despite the differences among the anomalous SST and LBC forcings prescribed from the nine AOGCMs. The similarities among the ensemble members 
(a)

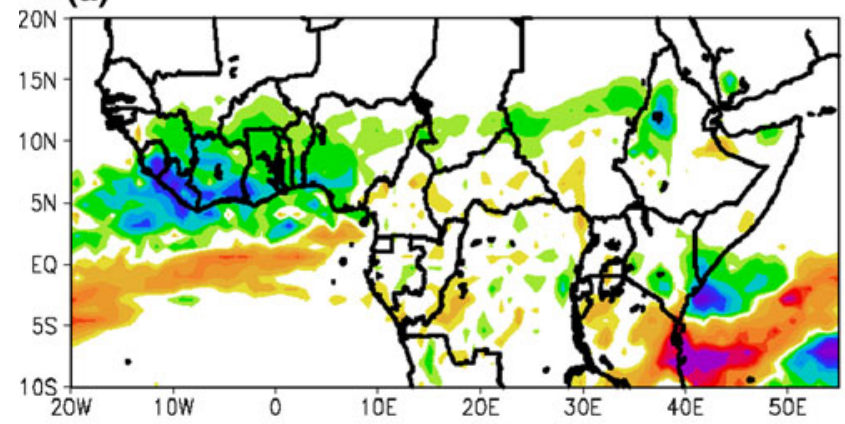

(c)

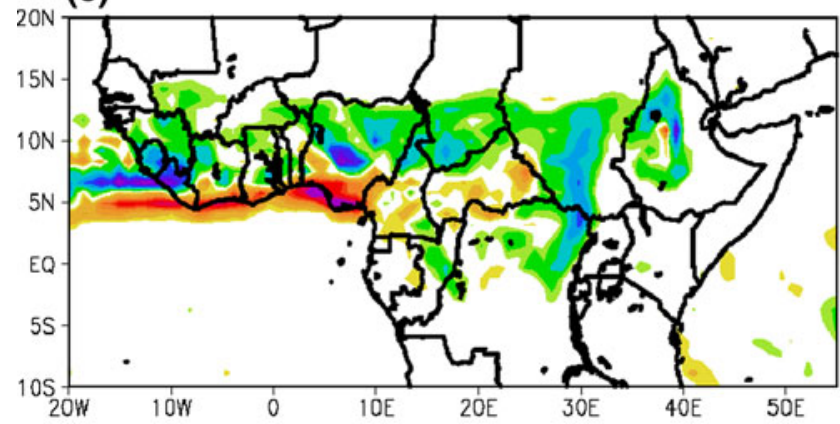

(e)

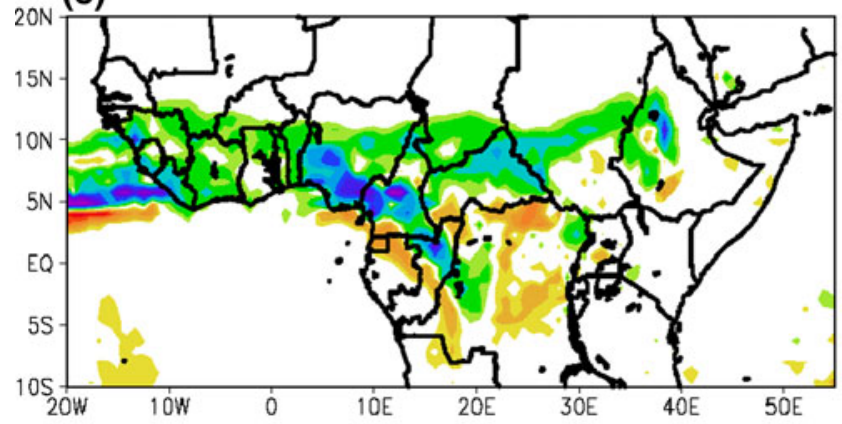

(b)

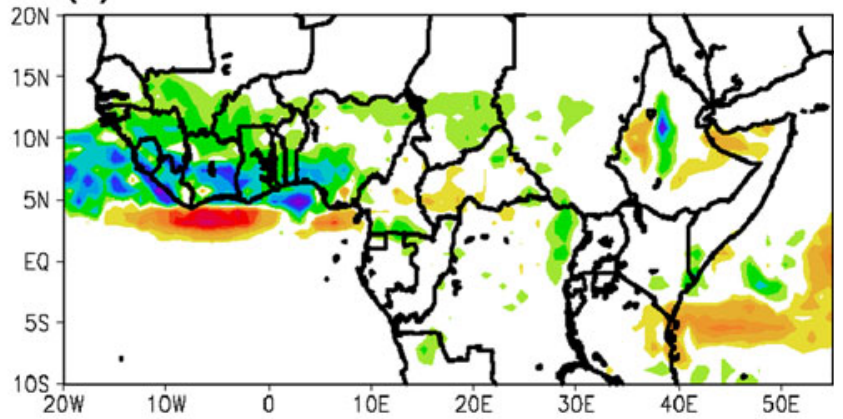

(d)

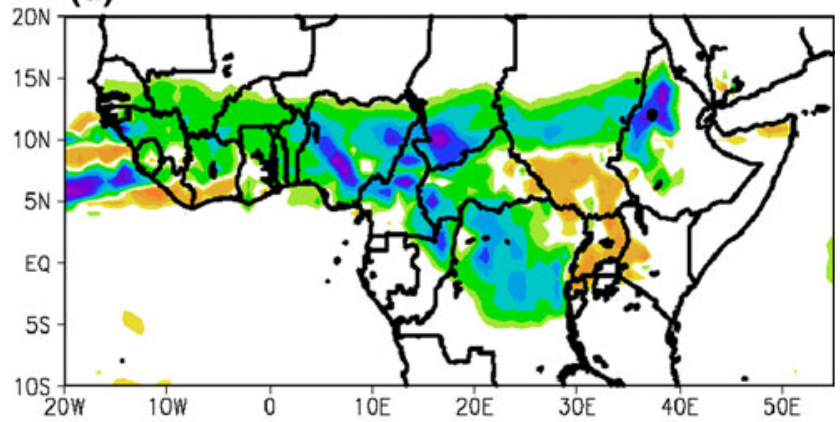

(f)

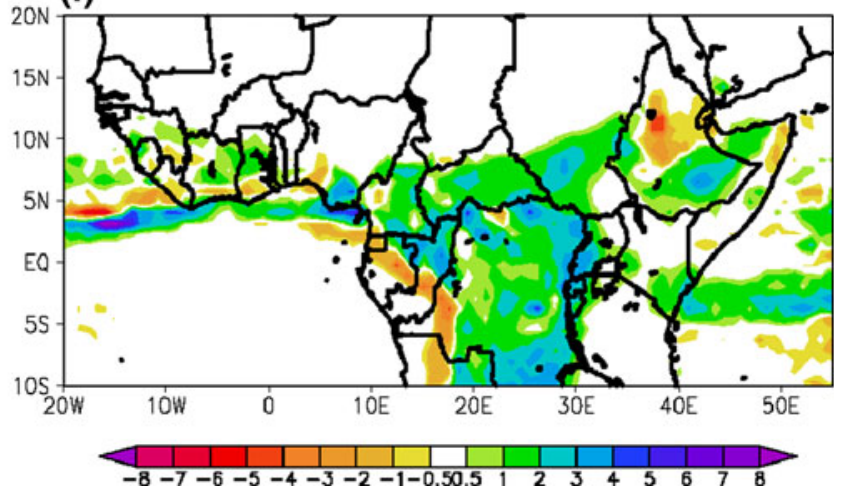

Fig. 12 Precipitation anomalies due to increasing the regional $\mathrm{CO}_{2}$ forcing from 330 ppm to 757 ppm $\left(\mathrm{CO}_{2}\right.$ only simulation minus control simulation) for (a) May, (b) June, (c) July, (d) August, (e) September, and (f) October. Units are mm/day

suggest that the simulated future climate is not sensitive to the details of the SSTA and LBCA constraints, rather that the similarities in predicted rainfall may be determined, to first order, by overall warming of the atmosphere and/or ocean. To test the hypothesis that the similarities in predicted rainfall are related to the overall warming of the ocean, we compare the monthly precipitation anomalies forced by each of the nine SSTA distributions taken from the AOGCMs (Fig. 14) to those due to a uniform $2 \mathrm{~K}$ warming of the ocean (Fig. 15).

During May and June, rainfall anomalies forced by the AOGCM SSTAs (Fig. 14a, b) and uniform 2K SSTAs (Fig. 15a, b) are similar east of $10^{\circ} \mathrm{E}$, with drying over the Sahel and central Africa and wetter conditions over East
Africa, suggesting that the overall ocean warming dominates the changes in SST gradients for this region. In contrast, AOGCM SSTA forcing produces drier conditions over West Africa, while anomalies are near zero or weakly positive due to the $2 \mathrm{~K}$ SSTA, indicating that changes in SST gradients play an important role in May and June.

The impact of SST warming dominates changes in SST gradients everywhere, even over West Africa, in July through September when the simulated rainfall anomalies under uniform 2K SST warming (Fig. 15c-e) are very similar to those from the AOGCM SSTAs (Fig. 14c-e). In July the east-west dipole, with dry (wet) conditions in western (eastern) Africa, is strikingly similar between the SSTA_only and 2K_SSTA simulations. During August and 
(a)

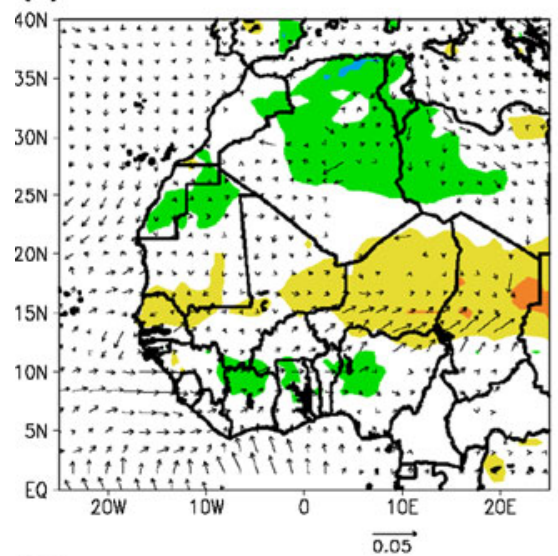

(d)

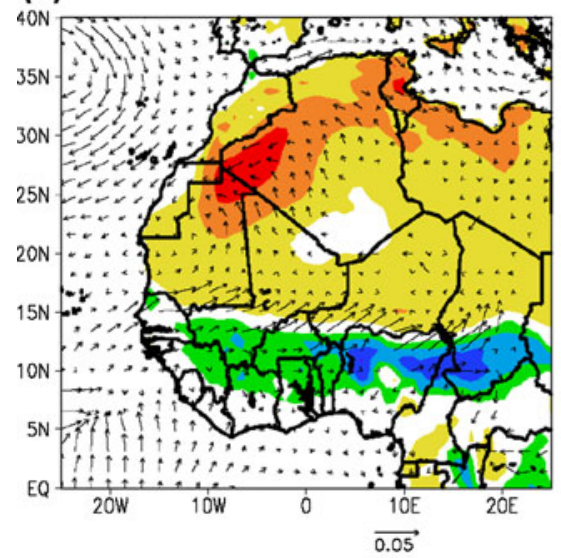

(b)

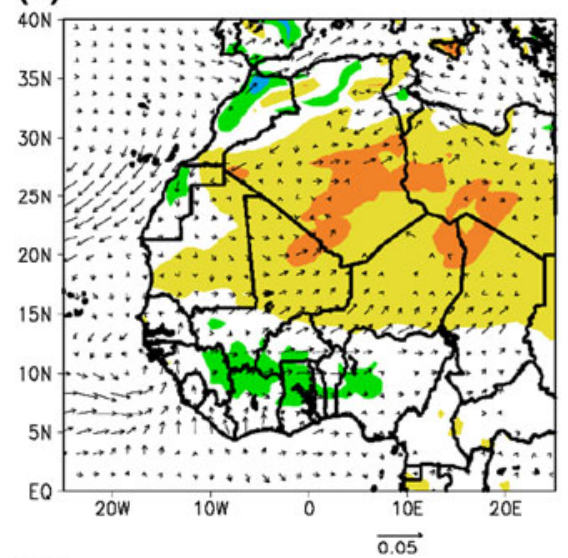

(e)

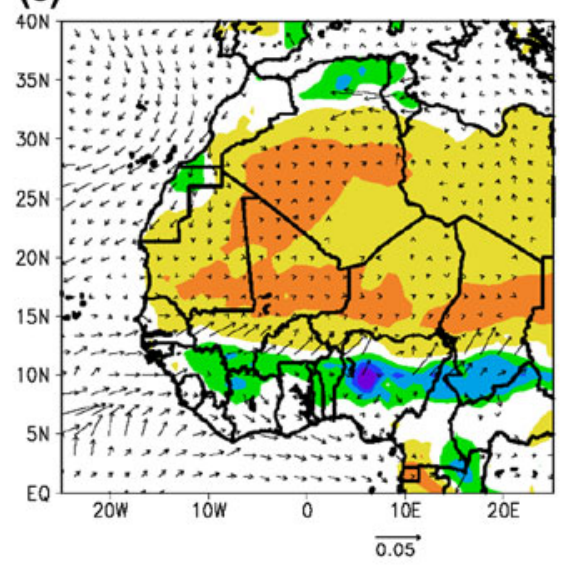

(c)

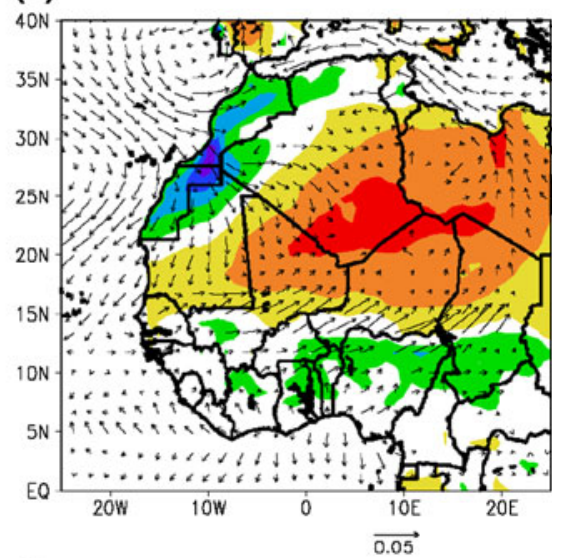

(f)

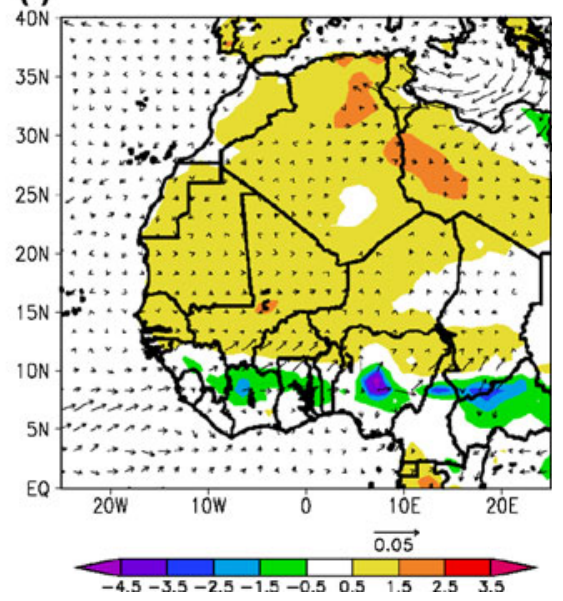

Fig. 13 Anomalies in surface temperature (shaded, $\mathrm{K})$ and moisture transport at $950 \mathrm{hPa}\left(\mathrm{kg}_{-} \mathrm{H}_{2} \mathrm{O}\right.$ kg_air $\left.{ }^{-1}\right)\left(\mathrm{m} \mathrm{s}^{-1}\right)$, vectors for (a) May, (b) June, (c) July, (d) August, (e) September, and (f) October from the $\mathrm{CO}_{2}$ only simulation

September both the predicted SSTAs and uniform 2K SST warming generate wetter conditions, with similarly placed maxima over Ethiopia and Kenya, central Sudan, and Nigeria, Togo, and Benin.

Rainfall anomalies are similar during October east of $10^{\circ} \mathrm{E}$, but they are different in West Africa where the AOGCM SSTAs produce an inconsistent or weakly positive signal and the $2 \mathrm{~K}$ SST warming produces weakly dry conditions. With the exception of West Africa during May, June, and October, the precipitation anomalies due to SSTAs from the nine AOGCMs (Fig. 14a, b, f) are similar to those due to uniform 2K SST warming (Fig. 15a, b, f), supporting the idea that for some regions of northern tropical Africa the overall warming of the oceans dominates the response due to the details of the predicted SSTAs. This may partly explain the high level of consistency among the ensemble members in the fully forced regional simulations.

To better understand the SSTA-forcing of precipitation anomalies for the end of the twenty-first century, correlations between area-averaged SSTAs over specific ocean regions and daily rainfall anomalies at each grid point are calculated for each of the nine fully forced future ensemble members. Figure 16a shows the ocean averaging regions, including the Mediterranean $\left(5^{\circ} \mathrm{W}-30^{\circ} \mathrm{E}\right.$ and $\left.30^{\circ} \mathrm{N}-42^{\circ} \mathrm{N}\right)$, northern Atlantic $\left(53^{\circ} \mathrm{W}-5^{\circ} \mathrm{W}\right.$ and $\left.10^{\circ} \mathrm{N}-47^{\circ} \mathrm{N}\right)$, equatorial Atlantic $\left(53^{\circ} \mathrm{W}-20^{\circ} \mathrm{E}\right.$ and $\left.10^{\circ} \mathrm{S}-10^{\circ} \mathrm{N}\right)$, southern Atlantic $\left(53^{\circ} \mathrm{W}-20^{\circ} \mathrm{E}\right.$ and $\left.32^{\circ} \mathrm{S}-10^{\circ} \mathrm{S}\right)$, northern Indian $\left(45^{\circ} \mathrm{E}-\right.$ $103^{\circ} \mathrm{E}$ and $\left.10^{\circ} \mathrm{N}-20^{\circ} \mathrm{N}\right)$, equatorial Indian $\left(45^{\circ} \mathrm{E}-103^{\circ} \mathrm{E}\right.$ and $\left.10^{\circ} \mathrm{S}-10^{\circ} \mathrm{N}\right)$, and southern Indian $\left(45^{\circ} \mathrm{E}-103^{\circ} \mathrm{E}\right.$ and $\left.32^{\circ} \mathrm{S}-10^{\circ} \mathrm{S}\right)$ basins. The ensemble-averaged correlations are shown in Figs. 16b-d and 17. Regions where the correlation is not significant at the $95 \%$ confidence level (twosided test) are shaded white, and regions where $<7$ of the 9 ensemble members agree on the sign of the correlation are shaded grey. Correlations are also calculated between SSTAs at each ocean grid point and area-averaged rainfall anomalies over the land regions defined in Fig. 2a (Fig. 18).

Ensemble members do not agree about the sign of the correlation of northern African rainfall with SSTAs over the northern Indian basin (Fig. 16b), but correlations over 
(a)

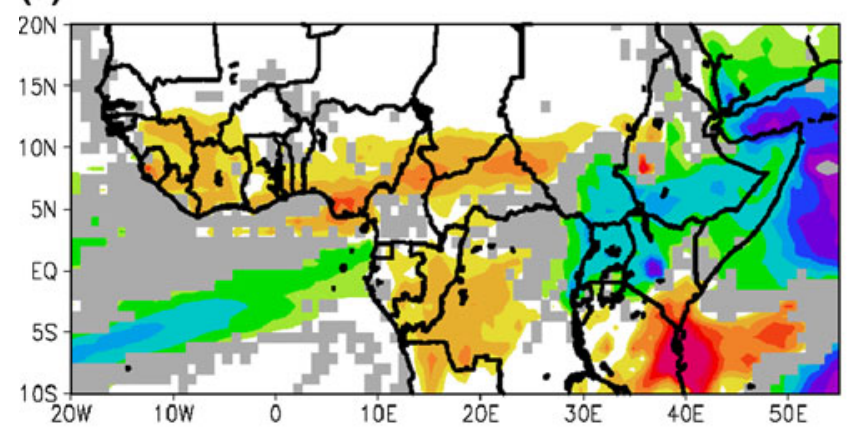

(c)

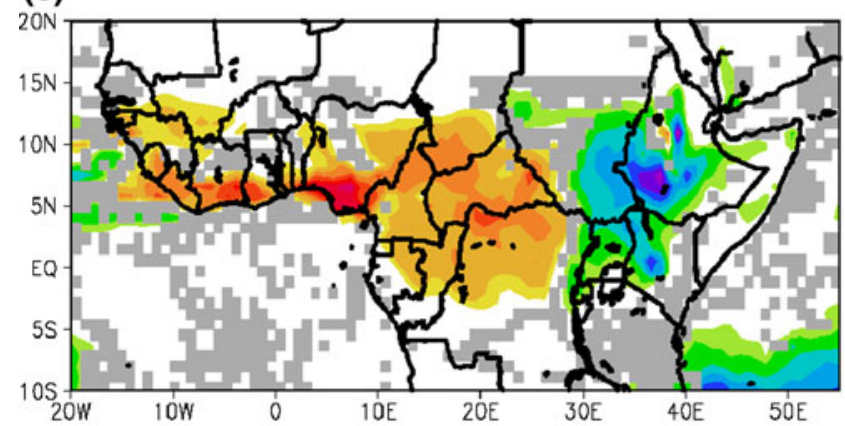

(e)

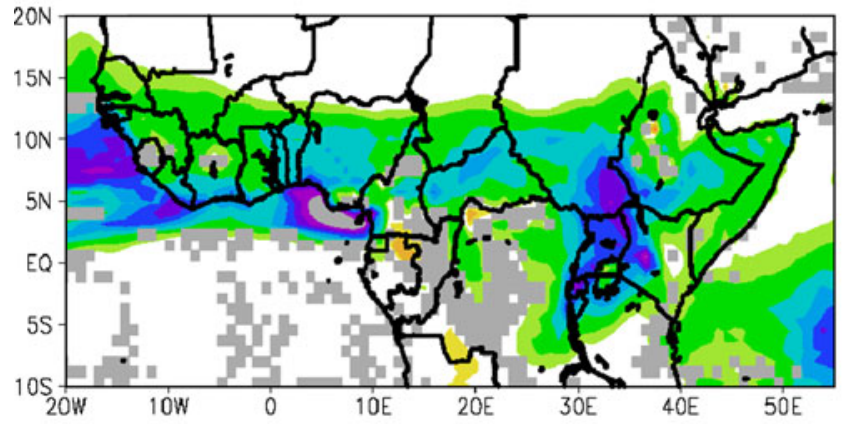

(b)

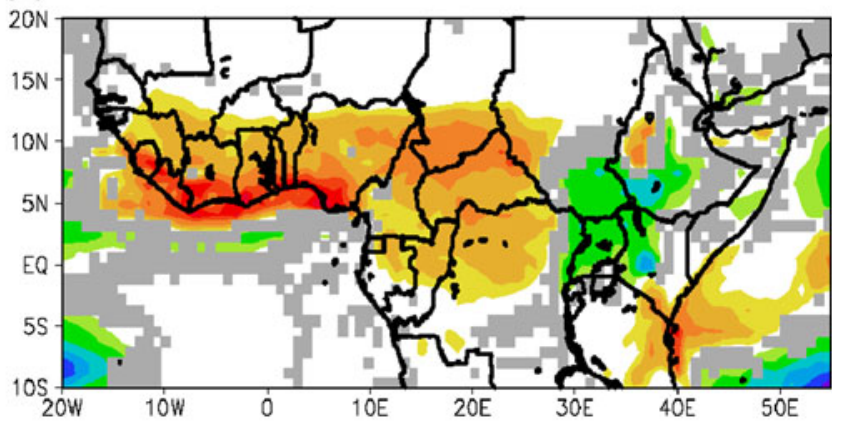

(d)

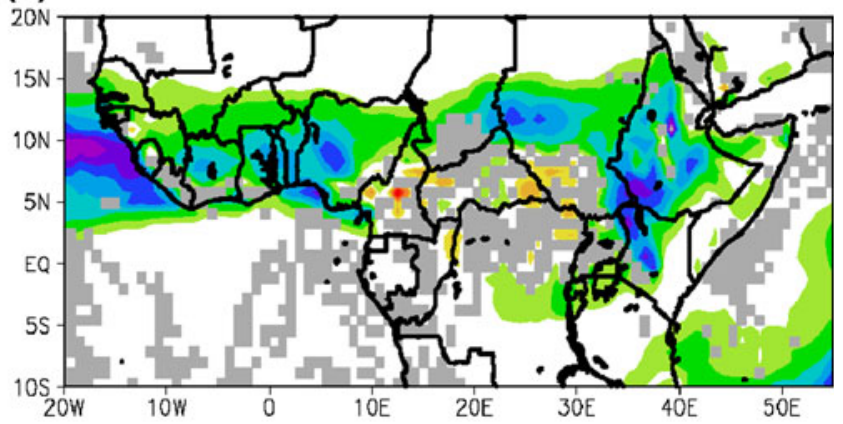

(f)

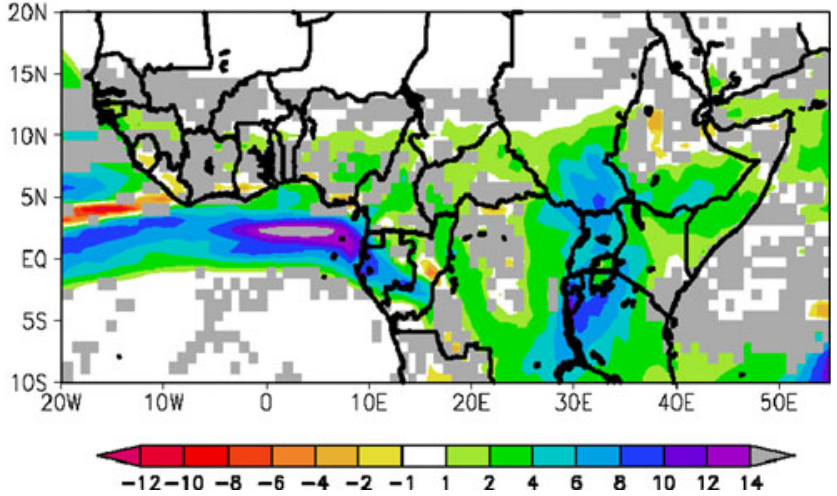

Fig. 14 Ensemble averaged precipitation anomalies from the SSTA_only simulations for (a) May, (b) June, (c) July, (d) August, (e) September, and (f) October. Units are $\mathrm{mm} / \mathrm{day}$. Areas where $<77 \%$ of the ensemble members agree are shaded grey

both the equatorial (Fig. 16c) and southern (Fig. 16d) Indian basins are significant. Sahelian precipitation is negatively correlated with SSTAs in both the equatorial and southern Indian Ocean regions, while precipitation over East Africa is positively correlated with SSTAs from only the southern Indian basin, most strongly around Madagascar (Fig. 18c). The negative correlation between Indian Ocean SSTAs and precipitation anomalies over the Sahel is consistent with our understanding of present day decadal-scale climate variability (Giannini et al. 2003; Bader and Latif 2003; Lu and Delworth 2005; Chung and Ramanathan 2006; Hagos and Cook 2008).

The RCM simulates significant positive correlations between northern Atlantic Ocean SSTAs and precipitation over the Sahel region, while northern Atlantic SSTAs are negatively correlated with rainfall anomalies over a small region along the Guinean Coast (Fig. 17a). Sahel rainfall anomalies are related to SSTAs over all of the northern tropical and subtropical Atlantic (Fig. 18b), while Guinean Coast rainfall anomalies are related to SSTAs over only the subtropical Atlantic (Fig. 18a). The regional model also produces a significant negative correlation between northern tropical and subtropical Atlantic SSTAs and precipitation over Eastern Africa (Figs. 17a, 18c).

There is little agreement among the ensemble members regarding the relationship between precipitation and SSTAs in the equatorial Atlantic (Fig. 17b) except for a 
(a)

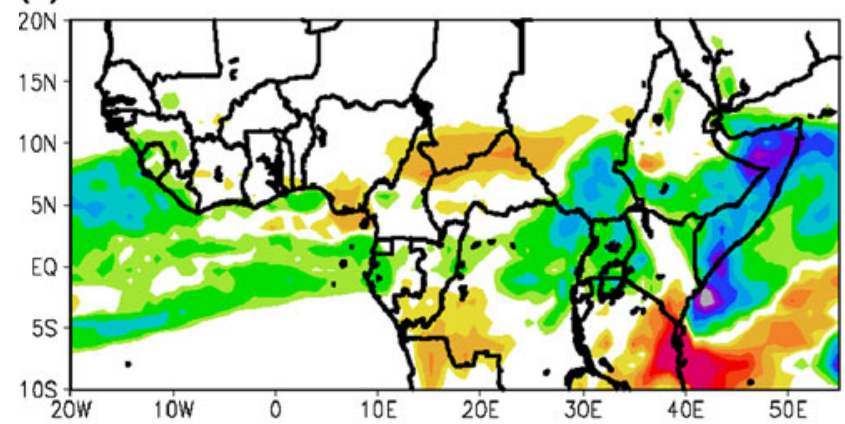

(c)

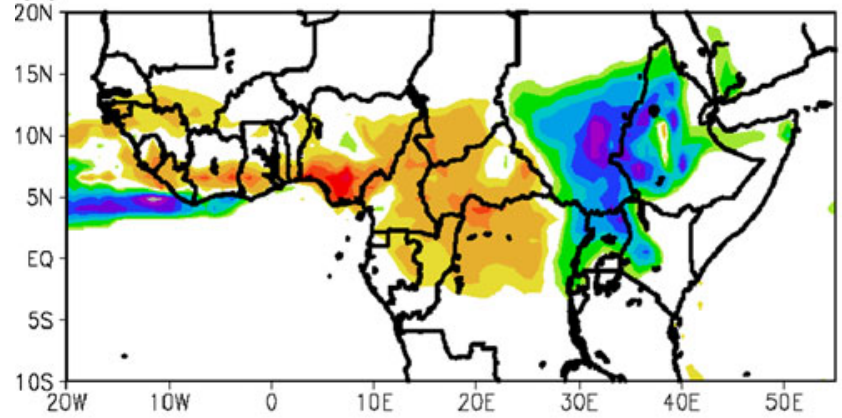

(e)

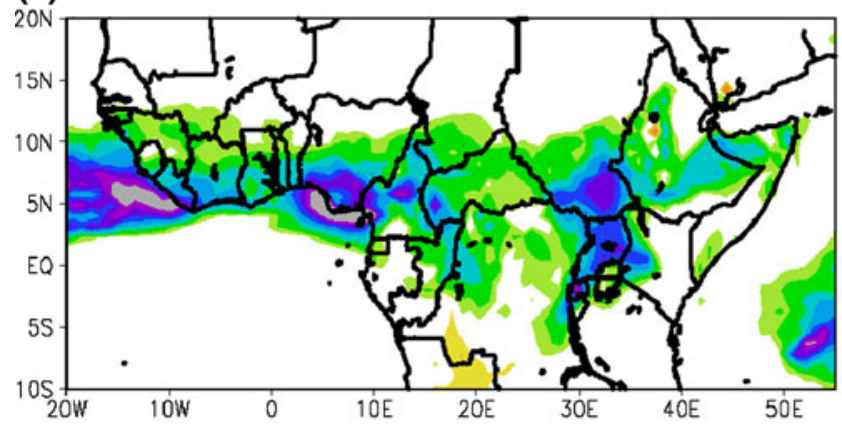

(b)

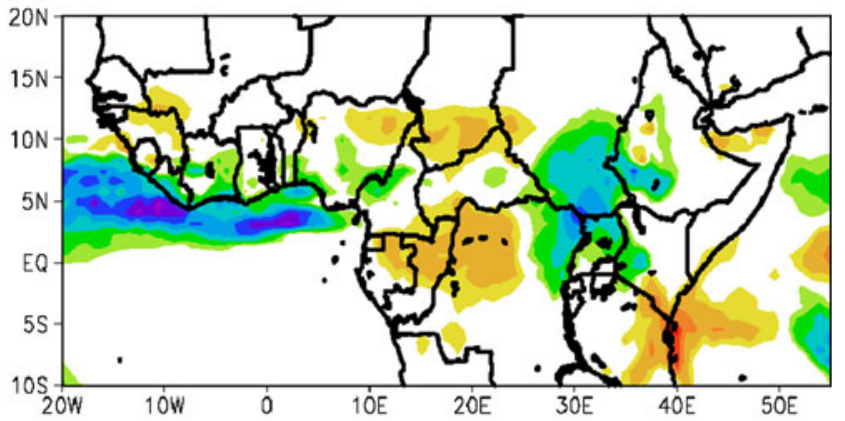

(d)

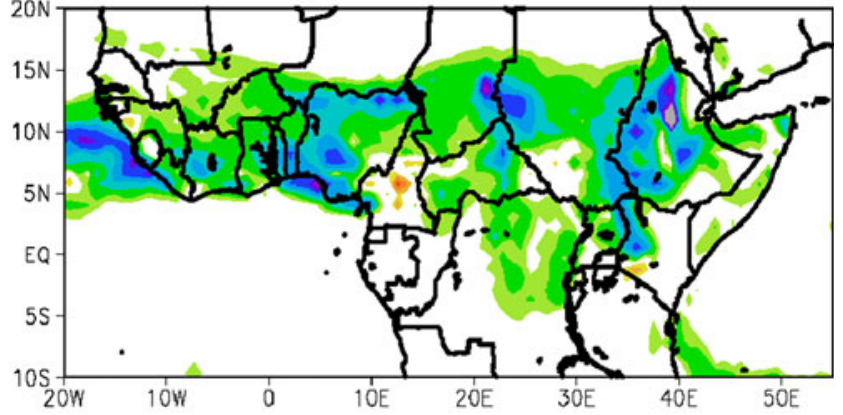

(f)

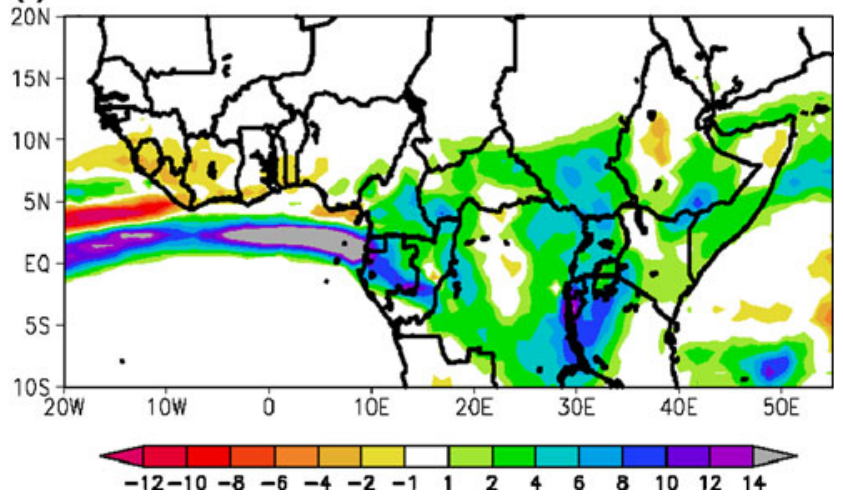

Fig. 15 Precipitation anomalies from the 2K_SST simulation for (a) May, (b) June, (c) July, (d) August, (e) September, and (f) October. Units are $\mathrm{mm} /$ day

positive correlation between Guinean Coast rainfall anomalies and Atlantic SSTAs between the equator and $5^{\circ} \mathrm{N}$ (Fig. 18a). SSTAs in the subtropical southern Atlantic are positively correlated with the simulated precipitation over the Guinean Coast region (Figs. 17c, 18a). The simulated relationship between northern and southern Atlantic SSTs and West African rainfall is consistent with our understanding of present day climate variability (Lamb 1978a, b; Folland et al. 1986, 1991; Druyan 1991; Lamb and Peppler 1992; Ward 1998; Vizy and Cook 2002) and emphasizes the importance of changes in SST gradients in simulating future West African rainfall in May, June, and October (Figs. 14a, b, $f$ and $15 a, b, f)$.
The relationship between SSTAs in the Mediterranean region and precipitation anomalies produced by the full future forcings (Fig. 17d) is similar to that of the northern Atlantic. The association between wetter conditions in the Sahel and drier conditions in the Guinean Coast region with warmer SSTAs in the Mediterranean simulated in the regional model is similar to the relationship found by Rowell (2003) and, as discussed in Sect. 4.2, the associated moisture transport anomalies that are observed with Mediterranean warming in the present day are relevant for future climate. The RCM also simulates a negative correlation between Mediterranean SSTs and rainfall over Uganda and southern Sudan. 

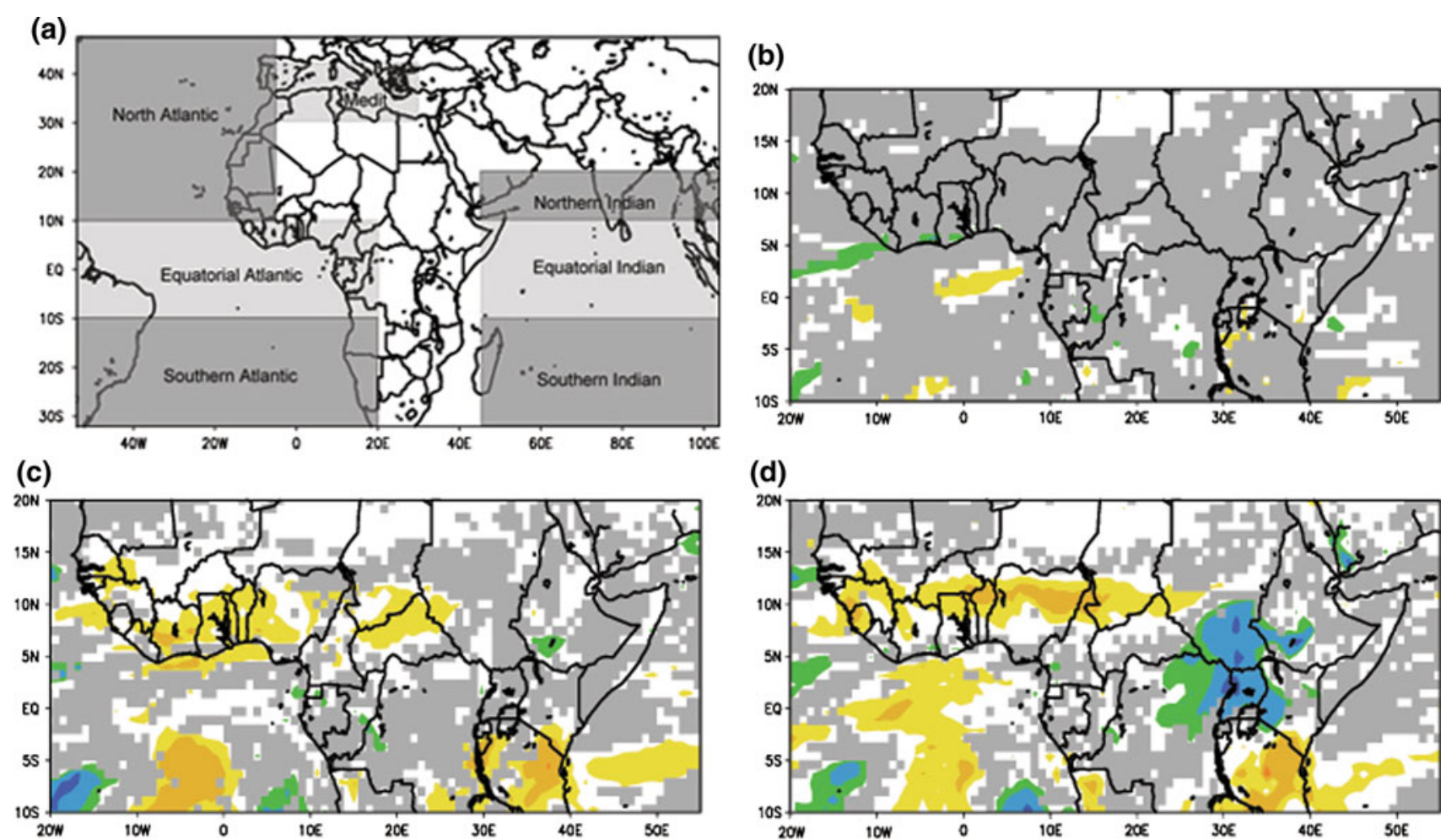

(d)

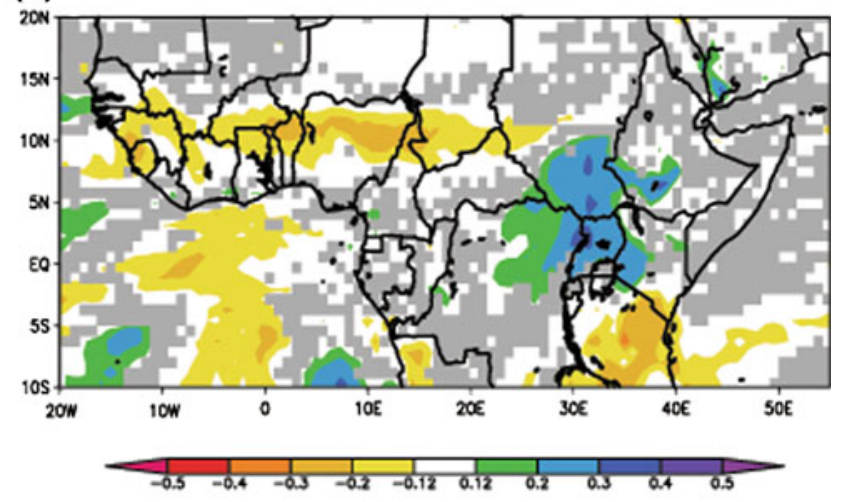

Fig. 16 (a) Ocean regions for correlations between SSTA and precipitation anomalies. Ensemble averaged correlation coefficients between daily precipitation anomalies at each grid point and areaaveraged SSTAs from the fully forced future simulations over the

\section{Conclusions}

Patricola and Cook (2010) develop a method for simulating future northern African climate that combines the strengths of regional and global modeling. An ensemble set of nine simulations representative of climate at 2081-2100 is performed with a regional climate model forced with increased atmospheric $\mathrm{CO}_{2}$ and anomalous SSTs and lateral boundary conditions derived from nine different AOGCMs. The high level of agreement among the ensemble members and the reasonable representation of the present day climate supports confidence in the climate predictions.

Here, we further evaluate and enhance confidence in these climate predictions by developing a physical understanding of the response. A sensitivity test confirms that the initialization of soil moisture and temperature in the regional simulations are not influential in the response.

Late twenty-first century rainfall anomalies over the Sahel include drying in June, and wetter conditions in August, September, and October. Anomalies in vertically integrated moisture convergence, as well as evaporation

(b) north Indian, (c) equatorial Indian, and (d) south Indian regions including May 1-October 31. White regions are insignificant at the $5 \%$ level (two sided test), and areas where $<77 \%$ of the ensemble members agree are shaded grey

and vertically integrated moisture advection, contribute significantly to the precipitation anomalies. A weaker West African westerly jet (WAWJ) and stronger African easterly jet support the summer drying. Wetter conditions in late summer and fall are sustained by positive atmospheric moisture anomalies carried by the WAWJ, as well as a strengthening of the jet itself, and anomalous moist flow from the Mediterranean region that is likely linked with SSTAs.

For the Guinean coast region wet conditions develop at the end of the twenty-first century in May and mid-August through October, with drying in June through mid-August. A moisture budget analysis shows that the rainfall anomalies are primarily supported by anomalies in both zonal and meridional moisture convergence. Drying in June through mid-August is related to a weaker and shallower southerly monsoon flow. Wetter conditions in May are associated with enhanced moisture transport by the southerly monsoon flow, but not a strengthening of the flow itself, while a monsoon flow that is stronger near the surface with a weaker return flow, as well as a strengthening of the low-level westerly flow and positive atmospheric 
(a)

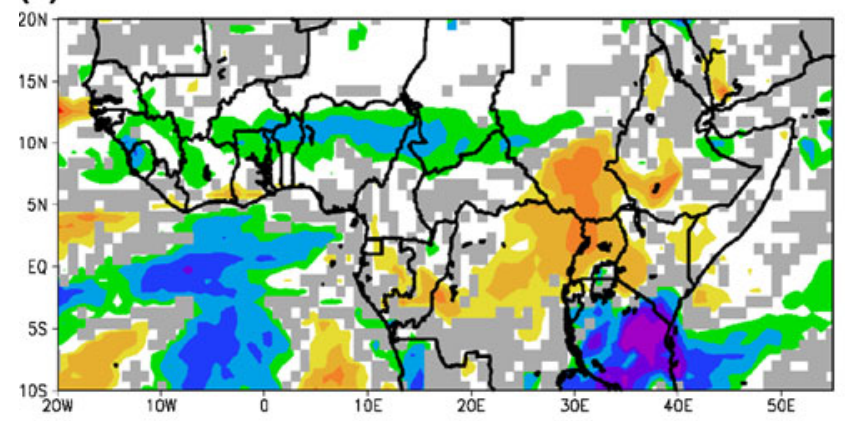

(c)

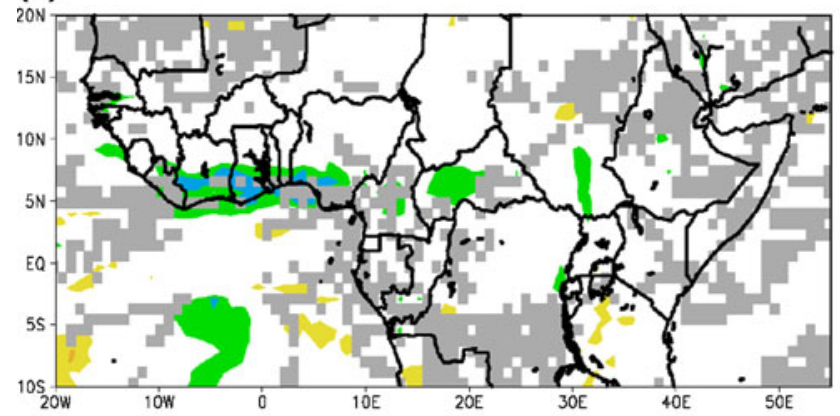

Fig. 17 Ensemble averaged correlation coefficients between daily precipitation anomalies at each grid point and area-averaged SSTAs from the fully forced future simulations over the (a) north Atlantic, (b) equatorial Atlantic, (c) south Atlantic, and (d) Mediterranean

moisture anomalies, support wetter conditions in midAugust through October. We note that the future drying signal in July and August may be related to an overestimation of rainfall in the control simulation, and may be an indication for future conditions in the Sahel.

Over the Uganda/Kenya/southern Sudan region in East Africa, severe drying in August and September at the end of the twenty-first century is related to a weakening of the Somali jet and Indian monsoon and a strengthening of the Turkana jet, and is partially supported by decreased evaporation. This relationship between East African and Indian rainfall is observed in present day climate variability and, given the strong relationship between these two regions, one should take note that a successful East African prediction depends on realistic control and future simulations over India. The RCM produces a reasonable simulation over India, however a rigorous validation comparable to that completed for Africa by PC10 was not completed.

Simulations which isolate the roles of the regional $\mathrm{CO}_{2}$ forcing and anomalous SST and lateral boundary constraints confirm that the spatial distribution of the rainfall predictions is primarily dominated by the SST and lateral boundary constraints. Over the Sahel, however, regional $\mathrm{CO}_{2}$ forcing plays an important secondary role, producing wetter conditions. The seasonal evolution of the Saharan (b)

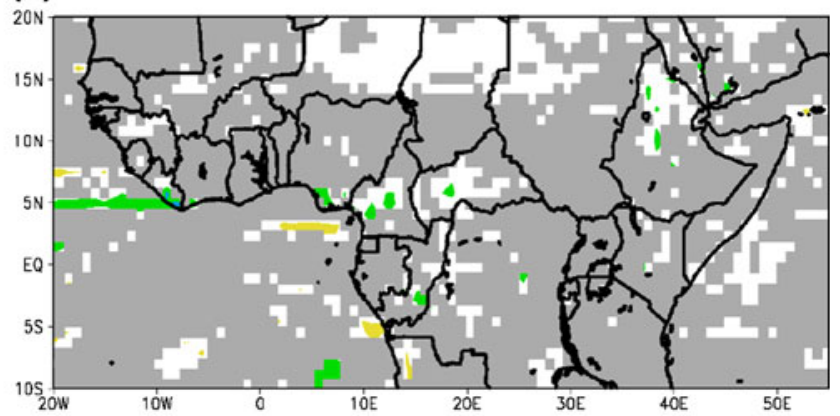

(d)

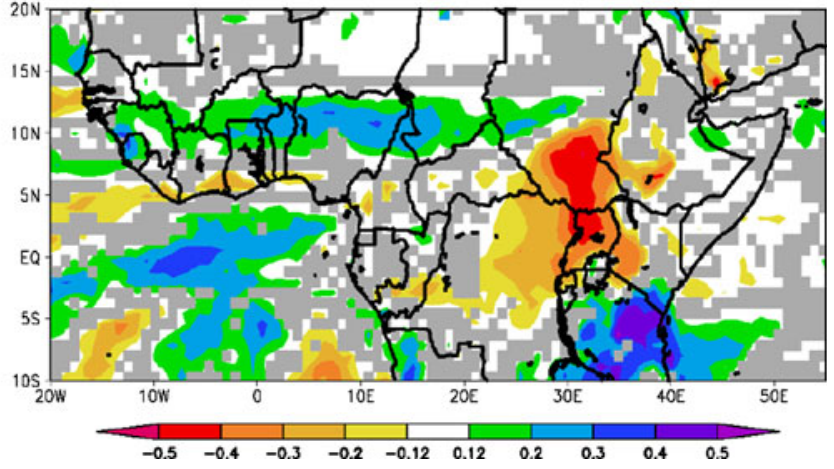

regions including May $1-$ October 31 . White regions are insignificant at the $5 \%$ level (two sided test), and areas where $<77 \%$ of the ensemble members agree are shaded grey

warming due to regional $\mathrm{CO}_{2}$ increases results in a peak intensification of the thermal low in July, with wind anomalies that carry moisture deeper into the Sahel from the south. Although the precipitation responses are similar in August, the physical mechanism due to increased regional $\mathrm{CO}_{2}$ is different than that produced by the full future forcings.

The similarities in rainfall anomalies between simulations constrained with only SSTAs from nine AOGCMs and a simulation with a uniform SST warming of $2 \mathrm{~K}$ suggest that the overall warming of the ocean may be in part controlling the consensus among the ensemble members of the fully forced future simulations over most regions. However, over West Africa in May, June, and October, changes in SST gradients play a more significant role.

The regional model simulations capture several of the observed relationships between rainfall and SST anomalies. These include a positive (negative) correlation between Sahelian rainfall and both Mediterranean and northern Atlantic (equatorial and southern Indian) SSTs, as well as a negative (positive) correlation between Guinean Coast rainfall and northern (southern) Atlantic SSTs. The presence of these relationships in the future simulations helps to better explain the predicted rainfall changes and, 

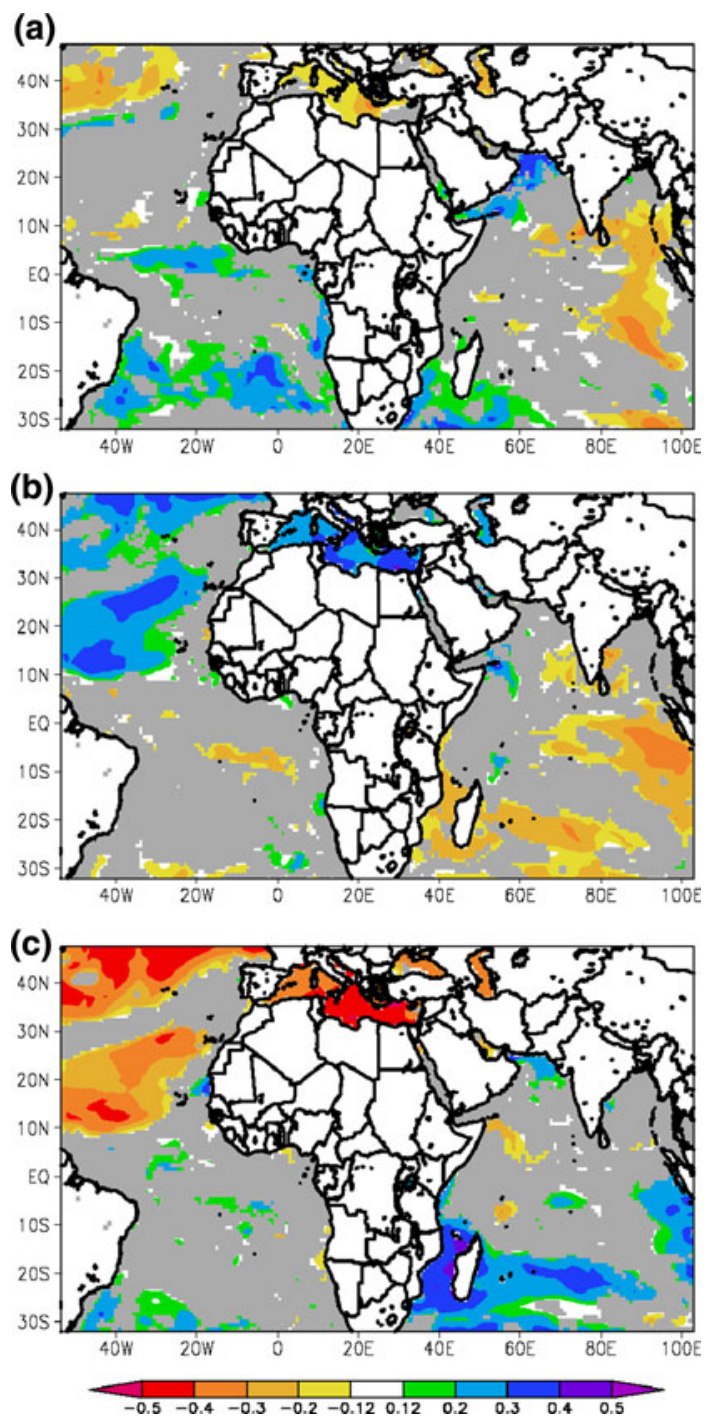

Fig. 18 Ensemble averaged correlation coefficients between SSTAs at each grid point and area-averaged daily precipitation anomalies from the fully forced future simulations over the (a) Guinean Coast, (b) Sahel, and (c) East African regions including May 1-October 31. Only regions over land are included in the averaging. White regions are insignificant at the 5\% level (two sided test), and areas where $<77 \%$ of the ensemble members agree are shaded grey

along with agreement among ensemble members, supports confidence in the predictions.

On seasonal timescales, the Sahelian rainfall predictions from the regional model are similar to those from the most recent AOGCM projections for the end of the twenty-first century. This study emphasizes the need for regional climate predictions on at least monthly timescales that rely not only on ensemble agreement and model validation, but also on our physical understanding of the predicted climate changes.

While these regional climate simulations have been carefully designed and tested to produce reliable predictions for the future, we note that there are some deficiencies in the control simulation, most notably the dry bias in the Sahel in July and August, and that the predictions are based on one regional model with one set of parameterizations. As discussed by PC10, another useful approach to further our understanding of climate change in sub-Saharan northern Africa would be to construct ensembles using different regional models (as in the ENSEMBLES and CORDEX projects) and/or sets of parameterizations, so long as reasonable control climates can be produced.

Acknowledgments We are grateful to the National Center for Atmospheric Research supercomputer facility, on which the simulations were run, and to the Program for Climate Model Diagnosis and Intercomparison, which has formed and maintained an archive of the IPCC AR4 AOGCM simulations. We are also grateful to the other members of our research group, Dr. Edward K. Vizy and Ms. Bing $\mathrm{Pu}$, for their comments and encouragement throughout the course of this project. We wish to thank two anonymous reviewers whose constructive comments have helped improve this paper.

Open Access This article is distributed under the terms of the Creative Commons Attribution Noncommercial License which permits any noncommercial use, distribution, and reproduction in any medium, provided the original author(s) and source are credited.

\section{References}

Bader J, Latif M (2003) The impact of decadal-scale Indian Ocean sea surface temperature anomalies on Sahelian rain-fall and the North Atlantic Oscillation. Geophys Res Lett 30:2169. doi: 10.1029/2003GL018426

Biasutti M, Sobel AH (2009) Delayed Sahel rainfall and global seasonal cycle in a warmer climate. Geophys Res Let 36:L23707. doi:10.1029/2009GL041303

Camberlin P (1997) Rainfall anomalies in the source region of the Nile and their connection with the Indian summer monsoon. J Clim 10:1380-1392

Chung CE, Ramanathan V (2006) Weakening of North Indian SST gradients and the monsoon rainfall in India and the Sahel. J Clim 19(10):2036-2045

Cook KH (1997) Large-scale atmospheric dynamics and Sahelian precipitation. J Clim 10(6):1137-1152

Cook KH (1999) Generation of the African easterly jet and its role in determining West African precipitation. J Clim 12(5):1165-1184

Cook KH (2008) Climate science: the mysteries of Sahel droughts. Nat Geosci 1(10):647-648

Cook KH, Vizy EK (2006) Coupled model simulations of the West African monsoon system: 20th Century simulations and 21st Century predictions. J Clim 19:3681-3703

Druyan LM (1991) The sensitivity of sub-Saharan precipitation to Atlantic SST. Clim Change 18:17-36

European Centre for Medium-Range Weather Forecasts (2002) The ERA-40 archive. ECMWF, Reading, p 40

Findlater J (1966) Cross-equatorial jet streams at low-levels over Kenya. Meteorol Mag 95:353-364

Findlater J (1977) Observational aspects of the low-level crossequatorial jet stream of the western Indian Ocean. Pure Appl Geophys 115:1251-1262

Folland CK et al (1986) Sahel rainfall and worldwide sea temperatures, 1901-1985. Nature 320:602-607 
Folland CK et al (1991) Prediction of seasonal rainfall in the Sahel region using empirical and dynamic methods. J Forecast 10(1-2):21-56

Fontaine B et al (1995) Rainfall anomaly patterns and wind field signals over West Africa in August (1958-1989). J Clim 8:1503-1510

Giannini A, Saravanan R, Chang P (2003) Oceanic forcing of Sahel rainfall on interannual to interdecadal time scales. Science 302(5647):1027-1030

Giannini A, Biasutti M, Held IM, Sobel AH (2008) A global perspective on African climate. Clim Change 90:359-383

Grist JP, Nicholson SE (2001) A study of the dynamic factors influencing the rainfall variability in the West African Sahel. J Clim 14:1337-1359

Grodsky SA, Carton JA, Nigam S (2003) Near surface westerly wind jet in the Atlantic ITCZ. Geophys Res Lett 30(19). doi: 10.1029/2003GL017867

Hagos SM, Cook KH (2008) Ocean warming and late-twentiethcentury Sahel drought and recovery. J Clim 21(15):3797-3814

Halpurn D, Woiceshyn PM (2001) Somali jet in the Arabian Sea, El Niño, and India rainfall. J Clim 14:434-441

Held IM, Delworth TL, Lu J, Findell KL, Knutson TR (2005) Simulation of Sahel drought in the 20th and 21st centuries. Proc Natl Acad Sci USA 102(50):17891-17896

IPCC (2000) Special report on emissions scenarios: a special report of working group III of the intergovernmental panel on climate change. In: Nakicenovic N, Swart R (eds) Cambridge University Press, Cambridge, UK, pp 570

IPCC (2007) Climate Change 2007: impacts, adaptation and vulnerability. In: Parry ML, Canziani OF, Palutikof JP, van der Linden PJ, Hanson CE (eds) Contribution of working group II to the fourth assessment report of the intergovernmental panel on climate. Cambridge University Press, Cambridge, UK, pp 976

Janicot S (1992) Spatiotemporal variability of West African rainfall. Part II. Associated surface and airmass characteristics. J Clim 5(5):499-511

Kalnay E et al (1996) The NCEP/NCAR 40-year reanalysis project. Bull Am Meteorol Soc 77:437-471

Kinuthia JH (1992) Horizonatal and vertical structure of the Lake Turkana Jet. J Appl Meteorol 31:1248-1274

Kinuthia JH, Asnani GC (1982) A newly found jet in North Kenya (Turkana Channel). Mon Weather Rev 110:1722-1728

Koster RD et al (2004) Regions of strong coupling between soil moisture and precipitation. Science 305(5687):1138-1140

Lamb PJ (1978a) Case studies of Tropical Atlantic surface circulation patterns during recent Sub-Saharan weather anomalies: 1967 and 1968. Mon Weather Rev 106:482-491

Lamb PJ (1978b) Large-scale tropical Atlantic surface circulation patterns associated with sub-Saharan weather anomalies. Tellus 30:240-251

Lamb JL, Peppler RA (1992) Further case studies of tropical Atlantic surface atmospheric and oceanic patterns associated with subSaharan drought. J Clim 5:476-488

Lenters JD, Cook KH (1995) Simulation and diagnosis of the regional summertime precipitation climatology in South America. J Clim 8:2988-3005

Lu J (2009) The dynamics of the Indian Ocean sea surface temperature forcing of Sahel drought. Clim Dyn 33:445-460

$\mathrm{Lu} \mathrm{J}$, Delworth TL (2005) Oceanic forcing of the late 20th century Sahel drought. Geophys Res Lett 32:L22706. doi:10.1029/ 2005GL023316

Maynard K, Royer JF (2004) Effects of "realistic" land-cover change on a greenhouse-warmed African climate. Clim Dyn 22:343-358

Meehl GA, Covey C, Delworth T, Latif M, McAvaney B, Mitchell JFB, Stouffer RJ, Taylor KE (2007) The WCRP CMIP3 multimodel dataset: a new era in climate change research. Bull Am Meteorol Soc 88:1383-1394. doi:10.1175/BAMS-88-9-1383

Moufouma-Okia W, Rowell DP (2010) Impact of soil moisture initialisation and lateral boundary conditions on regional climate model simulations of the West African Monsoon. Clim Dyn 35:213-229

Newell RE, Kidson JW (1984) African mean wind changes between Sahelian wet and dry periods. J Climatol 9:27-33

Nicholson SE (1980) The nature of rainfall fluctuations in sub-tropical West-Africa. Mon Weather Rev 108:473-487

Paeth H, Thamm HP (2007) Regional modeling of future African climate north of 15 degrees $\mathrm{S}$ including greenhouse warming and land degradation. Clim Change 83(3):401-427

Paeth H, Born K, Girmes R, Podzun R, Jacob D (2009) Regional climate change in tropical and Northern Africa due to greenhouse forcing and land use changes. J Clim 22:114-132

Patricola CM, Cook KH (2007) Dynamics of the West African monsoon under mid-Holocene precessional forcing: regional climate model simulations. J Clim 20(4):694-716

Patricola CM, Cook KH (2008) Atmosphere/vegetation feedbacks: a mechanism for abrupt climate change over northern Africa. J Geophys Res 113. doi:10.1029/2007JD009608

Patricola CM, Cook KH (2010) Northern African Climate at the end of the 21st Century: integrated application of regional and global climate models. Clim Dyn. doi:10.1007/s00382-009-0623-7

$\mathrm{Pu}$ BP, Cook KH (2010a) Dynamics of the West African westerly jet. J Clim (accepted)

Pu BP, Cook KH (2010b) Role of the West African westerly jet in Sahel precipitation variations on interannual and decadal time scales (in preparation)

Rowell DP (2003) The impact of Mediterranean SSTs on the Sahelian rainfall season. J Clim 16:849-862

Rowell JP et al (1995) Variability of summer rainfall over tropical North Africa (1906-1992): observations and modeling. Q J R Meteorol Soc 121:669-704

Segele ZT, Lamb PJ, Leslie LM (2009) Large-scale atmospheric circulation and global sea surface temperature associations with Horn of Africa June-September rainfall. Int $\mathbf{J}$ Climatol 29:1075-1100

Skamarock WC, Klemp JB, Dudhia J, Gill DO, Barker DM, Wang W, Powers JG (2005) A description of the advanced research WRF Version 2. NCAR tech. note, ncar/TN-468+STR, pp 88

Sultan B, Janicot S (2003) The West African monsoon dynamics. Part II. The "preonset" and "onset" of the summer monsoon. J Clim 16(21):3407-3427

Sun L, Semazzi FHM, Giorgi F, Ogallo L (1999) Application of the NCAR regional climate model to Eastern Africa 2. Simulation of interannual variability of short rains. J Geophys Res 104(D6):6549-6562

Vizy EK, Cook KH (2002) Development and application of a mesoscale climate model for the tropics: Influence of sea surface temperature anomalies on the West African monsoon. J Geophys Res 107. doi:10.1029/2001JD000686

Vizy EK, Cook KH (2003) Connections between the summer East Africa and Indian rainfall regimes. J Geophys Res 108(D16). doi:10.1029/2003JD003452

Ward MN (1998) Diagnosis and short-lead time prediction of summer rainfall in Tropical North Africa at interannual and multidecadal timescales. J Clim 11:3167-3191

Xue YK, Shukla J (1993) The influence of land-surface properties on Sahel climate. 1. Desertification. J Clim 6(12):2232-2245

Xue YK, Shukla J (1996) The influence of land surface properties on Sahel climate. 2. Afforestation. J Clim 9(12):3260-3275 